\title{
Automated Clean Chemistry for Bulk Analysis of Environmental Swipe Samples-Final Report
}

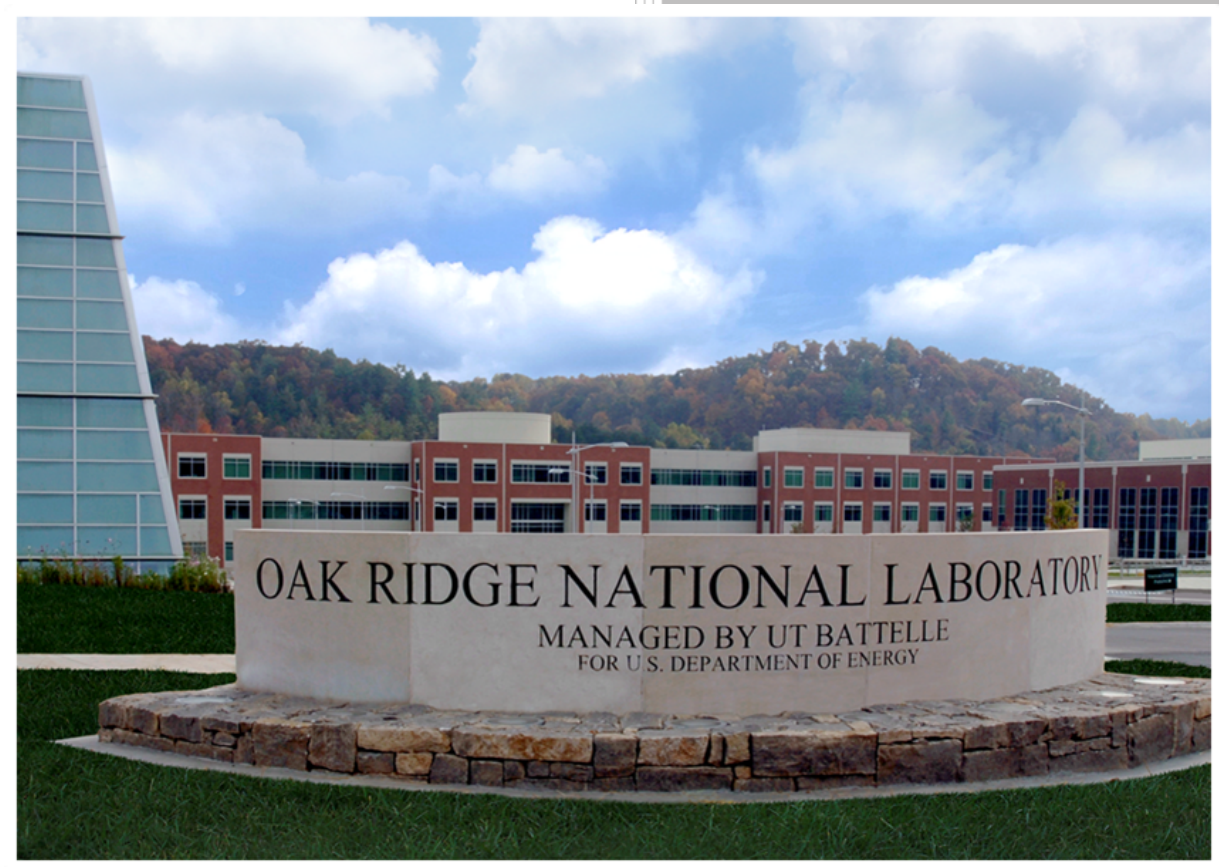

Brian W. Ticknor Shalina C. Metzger Eddy H. McBay Cole R. Hexel Kayron T. Rogers Debra A. Bostick

November 2018 


\section{DOCUMENT AVAILABILITY}

Reports produced after January 1, 1996, are generally available free via US Department of Energy (DOE) SciTech Connect.

Website www.osti.gov

Reports produced before January 1, 1996, may be purchased by members of the public from the following source:

National Technical Information Service

5285 Port Royal Road

Springfield, VA 22161

Telephone 703-605-6000 (1-800-553-6847)

TDD 703-487-4639

Fax 703-605-6900

E-mail info@ntis.gov

Website http://classic.ntis.gov/

Reports are available to DOE employees, DOE contractors, Energy Technology Data Exchange representatives, and International Nuclear Information System representatives from the following source:

Office of Scientific and Technical Information

PO Box 62

Oak Ridge, TN 37831

Telephone 865-576-8401

Fax 865-576-5728

E-mail reports@osti.gov

Website http://www.osti.gov/contact.html

This report was prepared as an account of work sponsored by an agency of the United States Government. Neither the United States Government nor any agency thereof, nor any of their employees, makes any warranty, express or implied, or assumes any legal liability or responsibility for the accuracy, completeness, or usefulness of any information, apparatus, product, or process disclosed, or represents that its use would not infringe privately owned rights. Reference herein to any specific commercial product, process, or service by trade name, trademark, manufacturer, or otherwise, does not necessarily constitute or imply its endorsement, recommendation, or favoring by the United States Government or any agency thereof. The views and opinions of authors expressed herein do not necessarily state or reflect those of the United States Government or any agency thereof. 
Chemical Sciences Division

\title{
AUTOMATED CLEAN CHEMISTRY FOR BULK ANALYSIS OF ENVIRONMENTAL SWIPE SAMPLES
}

\author{
Brian W. Ticknor \\ Shalina C. Metzger \\ Eddy H. McBay \\ Cole R. Hexel \\ Kayron T. Rogers \\ Debra A. Bostick
}

Date Published: November 2018

Prepared by

OAK RIDGE NATIONAL LABORATORY

Oak Ridge, TN 37831-6283

managed by

UT-BATTELLE, LLC

for the

US DEPARTMENT OF ENERGY

under contract DE-AC05-00OR22725 



\section{CONTENTS}

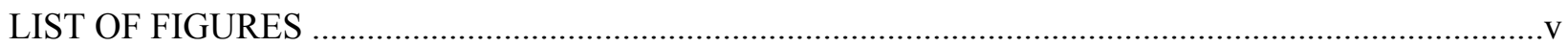

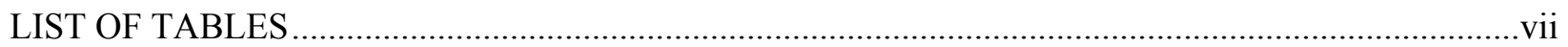

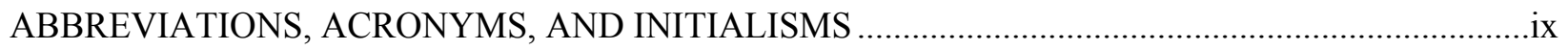

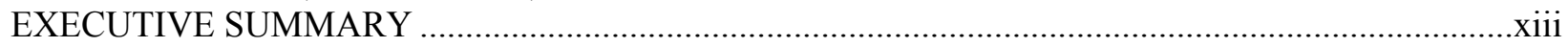

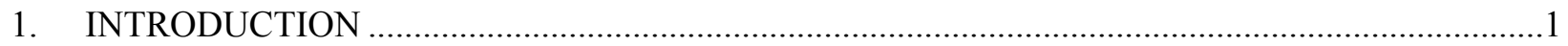

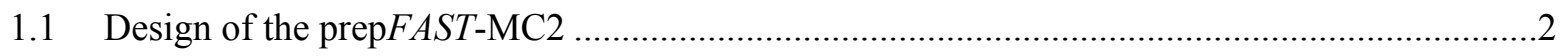

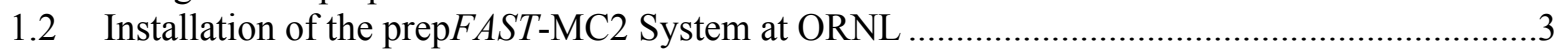

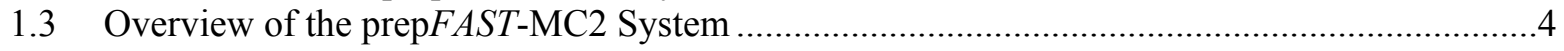

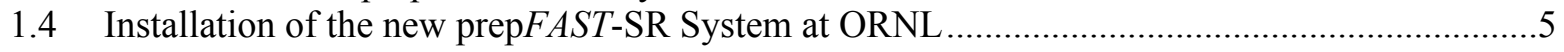

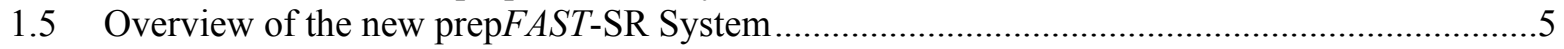

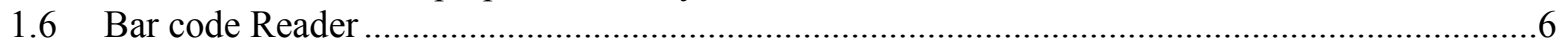

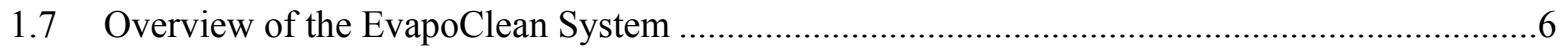

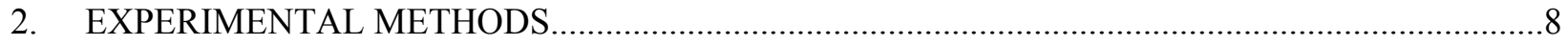

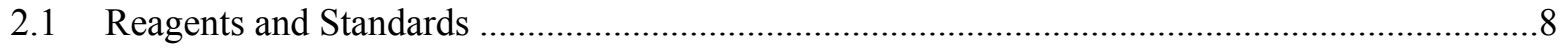

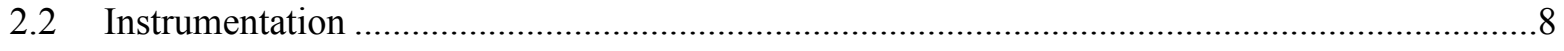

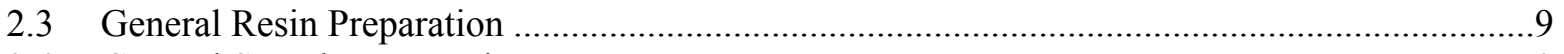

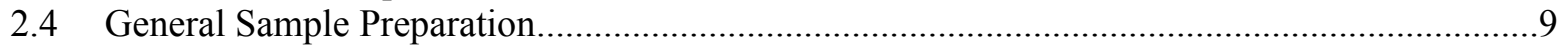

2.5 Original prepFAST-MC2 General Experimental Details .......................................................10

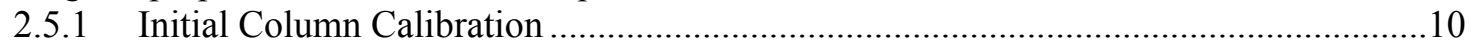

2.5.2 Column Packing and Unpacking Reproducibility ....................................................

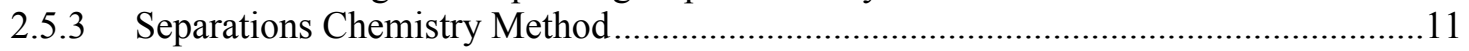

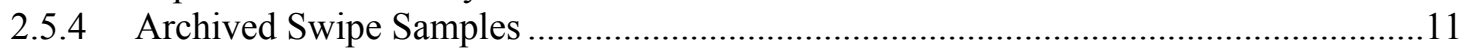

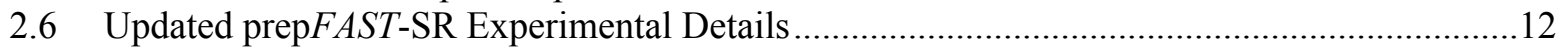

2.6.1 Validation Through CRM Separation ......................................................................12

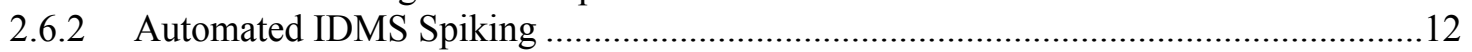

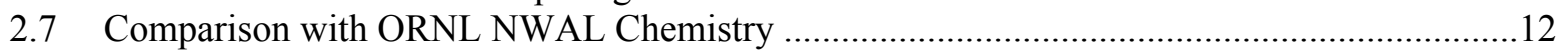

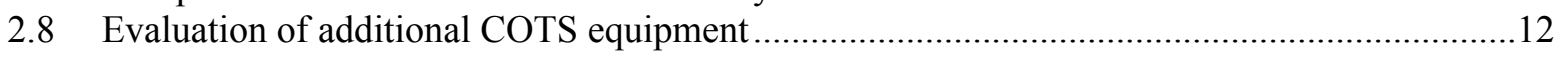

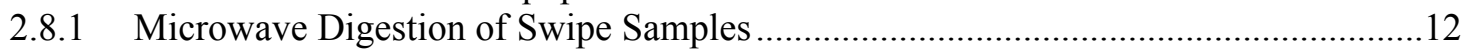

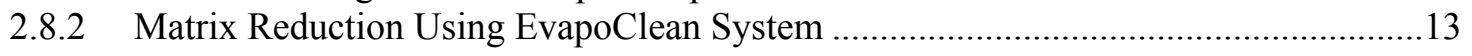

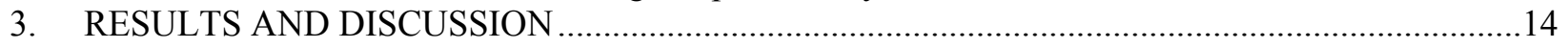

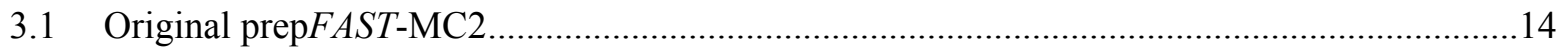

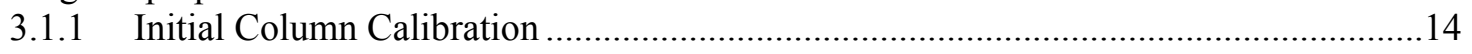

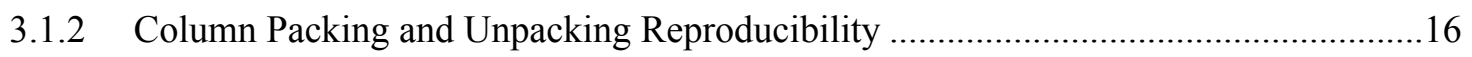

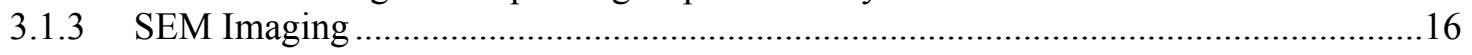

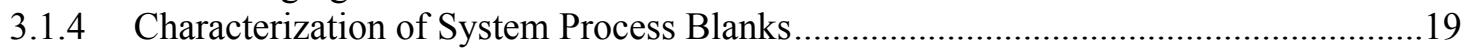

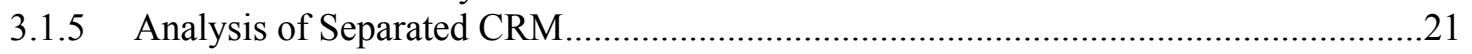

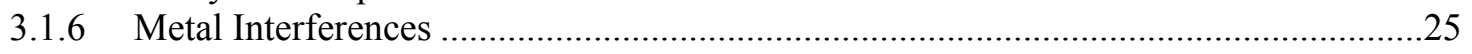

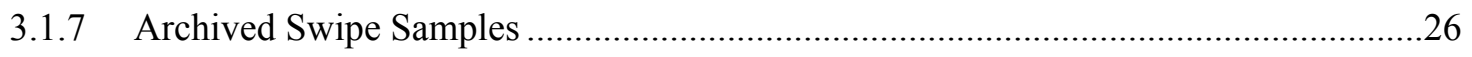

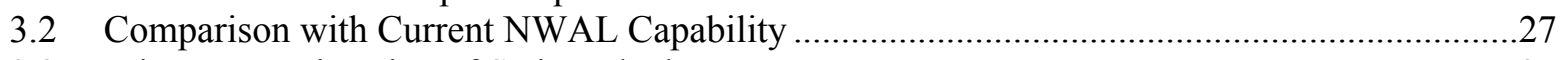

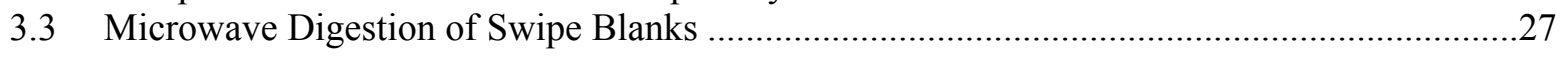

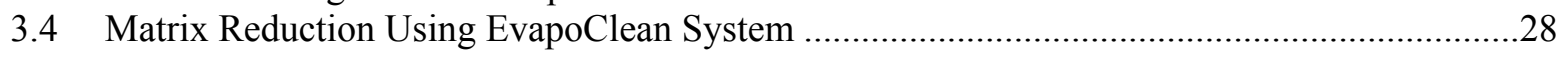

3.4.1 Reducing Background Counts through Leaching .................................................28

3.4.2 Decreasing Cross-Contamination via Sample Concentration in a Closed

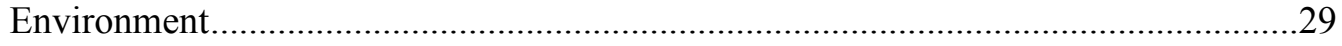

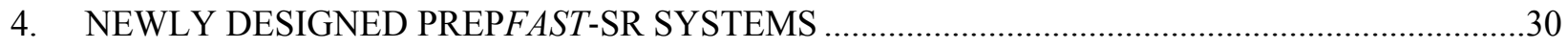

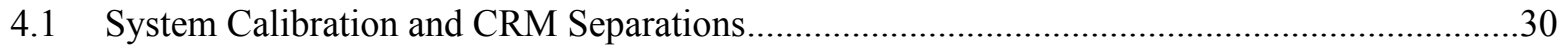

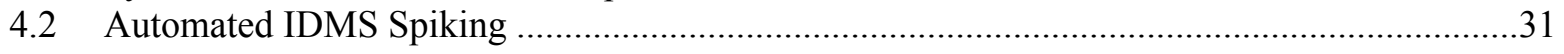

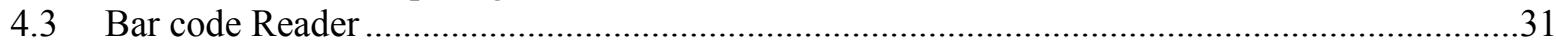




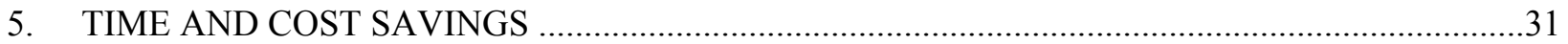

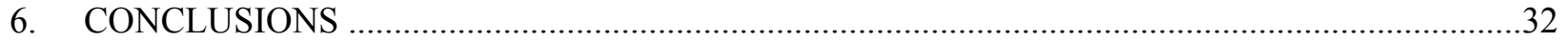

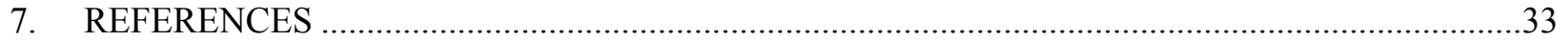

APPENDIX A. CEM MICROWAVE DIGESTION REPORT ….........................................................

APPENDIX B. prepFAST-SR STANDARD OPERATING PROCEDURE ............................................ 


\section{LIST OF FIGURES}

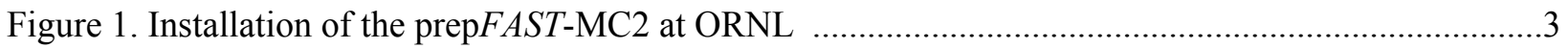

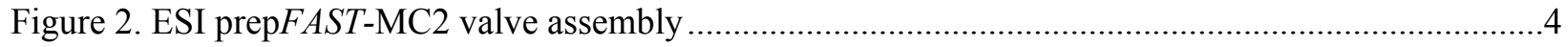

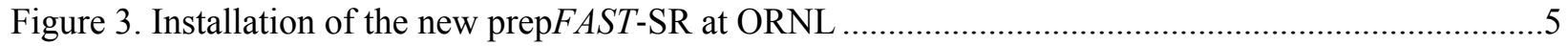

Figure 4. Highlighted updates to the prepFAST-SR: (A) ULPA filter at the top of the new enclosure; (B) updated valve assembly; (C) updated PFA columns; (D) bar code reader with specialized racks

Figure 5. The Analab EvapoClean installed in a chemical hood at ORNL ….........................................

Figure 6. Distillation and matrix reduction setup (A) and leaching setup (B) for the EvapoClean

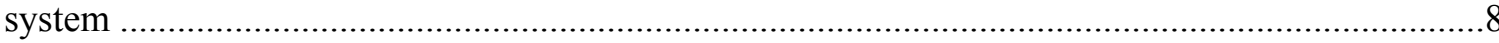

Figure 7. Individual column calibration elution profiles for $\mathrm{Pu}(\mathrm{A})$ and $\mathrm{U}(\mathrm{B})$ automated

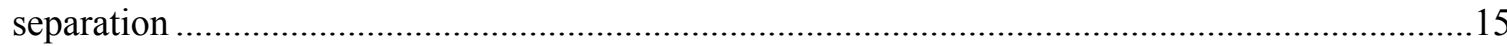

Figure 8. Combined UTEVA and TEVA column calibration runs for $\mathrm{U}$ (red) and $\mathrm{Pu}$ (blue)

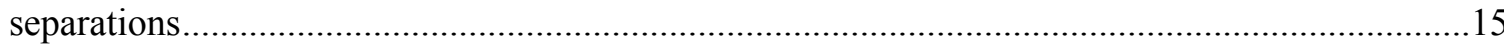

Figure 9. Packing of TEVA (C1) column (A) and UTEVA (C2) column (B) over 3 days using

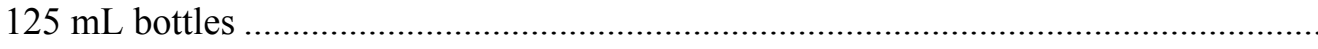

Figure 10. Comparison of SEM images of a new frit (Control), a frit after 14 separations on $\mathrm{C} 1$ with fast resin slurry stirring (A), and a frit after 21 separations on $\mathrm{C} 1$ with slow resin slurry stirring (B)

Figure 11. Comparison of SEM images of fresh TEVA resin (A) with fast stirring after $24 \mathrm{~h}$ (B) and slower stirring after $48 \mathrm{~h}(\mathrm{C})$

Figure 12. Total $\mathrm{U}$ in automated (red circle) and manual (blue triangle) process blanks with $2 \sigma$ error bars and average lines as determined by IDMS .

Figure 13. Total $\mathrm{Pu}$ in automated (red circle) and manual (blue triangle) process blanks with $2 \sigma$

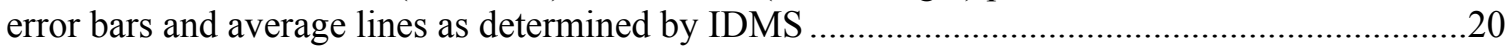

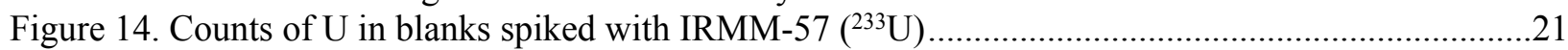

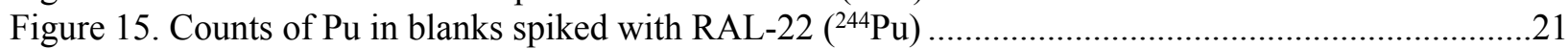

Figure 16. $\mathrm{U}$ M/C isotope ratios compared with instrument controls with $2 \sigma$ (green, dotted line) and $3 \sigma$ (red, dashed line) error lines for IRMM 183 instrument controls.

Figure 17. Pu M/C isotope ratios for NBL 137 with $2 \sigma$ error lines (red, dashed line) for NBL 137

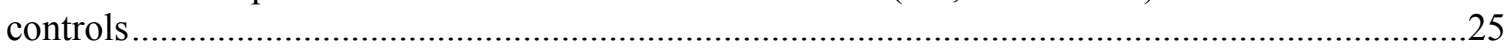

Figure 18. Comparison of background counts in three sets of PFA vials for selected isotopes .................28

Figure 19. Counts of selected isotopes from previously used PFA vials after conventional leaching and EvapoClean leaching method....

Figure 20. Percentage recovery of $U$ from matrix reduction using the EvapoClean system at various temperatures

Figure 21. Time comparison chart of ORNL NWAL manual chemistry and ESI prepFAST-MC2 automated system with total time and hands-on time shown 


\section{LIST OF TABLES}

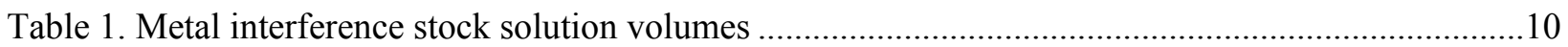

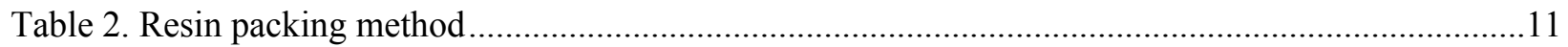

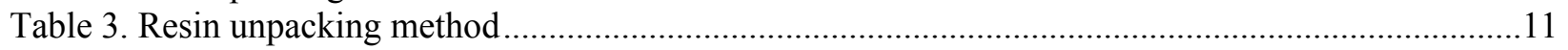

Table 4. Method description for the separation of U/Pu with the ESI system .........................................12

Table 5. Chemistry differences in the automated method and ORNL NWAL manual chemistry ..............13

Table 6. Furnace program for ashing cotton swipes .............................................................................13

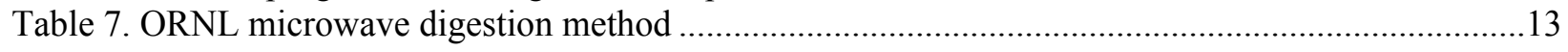

Table 8. Problems addressed in achieving reproducible renewable column generation ...........................16

Table 9. Approximate amounts of total U (IRMM-183) and Pu (NBL-137) CRMs in a sample for

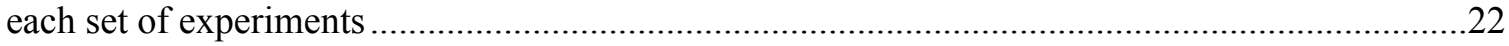

Table 10. Major and minor isotope ratios for $\mathrm{U}$ and $\mathrm{Pu}$ compared with $\mathrm{CRM}$ values during "initial

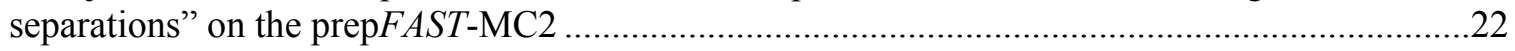

Table 11. Percentage reduction of contaminant elements in $\mathrm{U}$ and $\mathrm{Pu}$ fraction by the

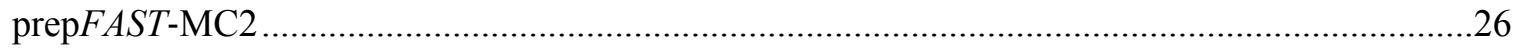

Table 12. Comparison of measured vs. reported values for major and minor $U$ isotopic ratios and major $\mathrm{Pu}$ isotopic ratios with $1 \sigma$ errors (N.D. is nondetectable) for archived ORNL environmental samples.

Table 13. Percentage recovery of selected metals that were evaporated at $130{ }^{\circ} \mathrm{C}$ from a metal concentration of $0.5 \mathrm{ppb}$ in $2 \% \mathrm{HNO}_{3}$

Table 14. Time comparison of ORNL NWAL manual chemistry and ESI prepFAST-MC2 automated system 



\section{ABBREVIATIONS, ACRONYMS, AND INITIALISMS}

$\begin{array}{ll}\text { ASTM } & \text { American Society for Testing and Materials } \\ \text { COTS } & \text { commercial off the shelf } \\ \text { CRM } & \text { Certified Reference Material } \\ \text { ESI } & \text { Elemental Scientific Incorporated } \\ \text { HR-ICP-MS } & \text { high-resolution inductively coupled plasma mass spectrometer } \\ \text { IAEA } & \text { International Atomic Energy Agency } \\ \text { ICPMS } & \text { inductively coupled plasma mass spectrometer } \\ \text { IDMS } & \text { isotope dilution mass spectroscopy } \\ \text { IRMM } & \text { Institute for Reference Materials and Measurements } \\ \text { ISO } & \text { International Standards Organization } \\ \text { JCR-EC } & \text { Joint Research Center of the European Commission } \\ \text { LDPE } & \text { low density polyethylene } \\ \text { M/C } & \text { measured/certified } \\ \text { MC-ICP-MS } & \text { multi-collector inductively coupled plasma mass spectrometer } \\ \text { MC-TIMS } & \text { multi-collector thermal ionization mass spectrometer } \\ \text { NBL } & \text { New Brunswick Laboratory } \\ \text { NIST } & \text { National Institute of Standards and Technology } \\ \text { NWAL } & \text { Network of Analytical Laboratories } \\ \text { ORNL } & \text { Oak Ridge Nation Laboratory } \\ \text { PFA } & \text { perfluoroalkoxy alkane } \\ \text { PSI } & \text { pounds per square inch } \\ \text { Pu } & \text { plutonium } \\ \text { SEM } & \text { scanning electron microscope } \\ \text { SOP } & \text { standard operating procedure } \\ \text { SRM } & \text { Standard Reference Material } \\ \text { U } & \text { uranium } \\ \text { ULPA } & \text { ultra-low particulate air } \\ & \end{array}$





\section{ACKNOWLEDGMENTS}

The authors would like to thank Paul Field and Hwan Kim of Elemental Scientific Inc. for providing the prepFAST-MC and the prepFAST-SR, as well as for troubleshooting guidance throughout this work. The authors would also like to thank Dr. Christopher P. Milojevich at Oak Ridge National Laboratory for collecting the scanning electron microscope images.

This work is supported by the Safeguards Technology Development Program, Office of Nonproliferation and Arms Control, at the Department of Energy's National Nuclear Security Administration under contract DE-AC05-00OR22725 with UT-Battelle LLC. 



\section{EXECUTIVE SUMMARY}

Sample preparation methods for mass spectrometry are being automated using commercial-off-the-shelf (COTS) equipment to shorten lengthy and costly manual chemical purification procedures. This development addresses a serious need in the International Atomic Energy Agency's (IAEA) Network of Analytical Laboratories (NWAL) to increase efficiency in the Bulk Analysis of Environmental Samples for Safeguards program with a method that allows unattended, overnight operation. In collaboration with Elemental Scientific Inc. (ESI), the prepFAST-MC2 was designed based on COTS equipment. It was modified for uranium/plutonium separations using renewable columns packed with Eichrom TEVA ${ }^{\circledR}$ and UTEVA ${ }^{\circledR}$ resins, with a chemical separation method based on the Oak Ridge National Laboratory (ORNL) NWAL chemical procedure.

Initial verification of individual columns yielded small elution volumes with consistent elution profiles and good recovery. Combined column calibration demonstrated ample separation without crosscontamination of the eluent. Automated packing and unpacking of the built-in columns initially showed $>15 \%$ deviation in resin loading by weight, which can lead to inconsistent separations. Optimization of the packing and unpacking methods led to a reduction in the variability of the packed resin to less than $5 \%$ daily.

Based on the initial experience at ORNL with the prepFAST-MC2, a second-generation model, the prep $F A S T$-SR, was built by ESI. The newly designed prep $F A S T$-SR has several upgrades compared with the original prepFAST-MC2. The upgrades largely addressed issues with the reliability of unpacking the Eichrom columns and with ventilation to ensure adequate removal of acid vapors. Both systems are currently installed in the Ultra-Trace Forensics Science Center at ORNL.

Separations of mixed uranium and plutonium samples containing certified reference materials were analyzed by multi-collector inductively coupled plasma mass spectrometry and yielded good results. Current efforts have demonstrated a wider applicability of the prepFAST system. Near-quantitative removal of metal interferences was achieved with the system in both uranium and plutonium separated fractions. Successful system validation was completed with several archived samples. Isotopic results from archived samples and certified reference materials were well within data quality limits for the IAEA NWAL. Additional COTS equipment has been evaluated for its potential to aid the prepFAST-SR system in reducing the time allotments and cleanroom infrastructure requirements for accurate separations. Overall, these efforts help ensure continued efficient and effective operation of the NWAL.

Comparison of the amount of personnel time necessary for successful manual vs. automated chemical separations showed a significant decrease in hands-on time from 9.8 hours to 35 minutes for seven samples, respectively. This documented time savings and reduced labor translates to a significant cost savings per sample. Overall, the system will enable faster sample reporting times at reduced cost by limiting personnel hours dedicated to the chemical separation. 


\section{INTRODUCTION}

Streamlining sample preparation methods for mass spectrometry by the introduction of fully automated, commercial-off-the-shelf (COTS) equipment would address a serious need in the safeguards community by speeding up lengthy and costly manual chemical purification procedures. Presently, the International Atomic Energy Agency (IAEA), and its associated Network of Analytical Laboratories (NWAL), uses mass spectrometry as a key analysis technique in the bulk environmental sampling program. The current method for analysis of swipe samples uses high-precision multi-collector mass spectrometry to produce highly accurate and precise isotopic data. To reduce interferences and minimize matrix effects, extensive purification procedures are used to isolate actinide elements from their natural matrices. Purification protocols require manually loading gravity-driven separation columns, a process that is both expensive and time-consuming. Automating chemical separation, while still producing a highly purified sample, will offer significant savings in both time and money to the IAEA without sacrificing data quality. Finally, the use of COTS equipment will allow an automated method to be quickly and economically transferred to and implemented by any NWAL laboratory, helping the IAEA globally execute standard operating procedures (SOP) for isotopic purification while addressing the ongoing challenges of backlogged samples.

Environmental swipes are one type of sample that the IAEA may collect, during inspections of facilities under safeguards, to verify compliance with declared nuclear activities. ${ }^{1}$ NWAL laboratories perform destructive analysis of exposed cotton swipe samples acquired during on-site inspections of safeguarded facilities to aid IAEA in making bias defect determinations ${ }^{1}$ where small amounts of nuclear material may be missing. Actinide elements, particularly uranium $(\mathrm{U})$ and plutonium $(\mathrm{Pu})$, are measured for isotopic composition and concentration. Bulk analysis is a form of destructive analysis that is performed on an entire swipe sample. It uses high-precision mass spectrometry of purified samples to measure the isotopic composition and concentration of the actinide elements, particularly $\mathrm{U}$ and $\mathrm{Pu}$, collected on the swipe. Bulk analysis produces very accurate and precise data, but the chemical separations required to produce the purified samples are labor intensive and require significant laboratory infrastructure. The IAEA depends heavily on the NWAL to support the Bulk Analysis of Environmental Samples for Safeguards program. Timeliness and efficient sample processing are important for the NWAL facilities. Typical characteristics of collected field samples are $1 \mathrm{ng}$ to $10 \mathrm{mg}$ U per swipe and $<1 \mathrm{ng} \mathrm{Pu}$ per swipe. The Measurement Quality Goals set forth by the IAEA for the bulk analysis program are a $\leq 2 \%$ relative expanded uncertainty for ${ }^{235} \mathrm{U} /{ }^{238} \mathrm{U}$, and $\leq 20 \%$ for ${ }^{234} \mathrm{U} /{ }^{238} \mathrm{U}$, and ${ }^{236} \mathrm{U} /{ }^{238} \mathrm{U}$ at $>10 \mathrm{ng} \mathrm{U}$, and $\leq 20 \%$ for all $\mathrm{Pu}$ isotope ratios at $>1 \mathrm{pg}$ at a $95 \%$ confidence level. ${ }^{2}$

Measurements of environmental samples are typically made by either multi-collector inductively coupled plasma mass spectrometry (MC-ICP-MS) or multi-collector thermal ionization mass spectrometry (MCTIMS). However, these high-precision instruments require highly purified actinide fractions, free from interferences such as organics and heavy metals, to ensure the quality of the measurements. Current purification protocols include ashing samples individually in furnaces (or occasionally, chemical leaching with acid) and then manually loading gravity-driven separation columns-a process that is both costly and time consuming. From start to finish, the manual purification chemistry takes between 2 and 4 weeks and represents the longest single step in the analysis process for bulk environmental samples. The separation procedures are also typically carried out in certified International Standards Organization (ISO) cleanroom laboratories with heavily filtered air and high-purity reagents to limit the contribution of background contamination to the measurement of the nanograms or picograms of material that may be present in environmental samples. The installation and maintenance of cleanroom facilities represent a significant upfront financial investment and ongoing maintenance commitments that some laboratories may be unable to sustain. 
Streamlining NWAL sample preparation methods for subsequent analysis by mass spectrometry using fully automated, COTS equipment would address a serious need in the safeguards community by shortening lengthy, costly manual chemical digestion and purification procedures. Automating digestion and chemical separation, while still producing a highly purified sample fraction, would offer significant time and cost savings to the IAEA without sacrificing data quality.

The goal of this project is to automate the chemical separations of $\mathrm{U}$ and $\mathrm{Pu}$ in environmental samples with a system that allows unattended, overnight operation. Automation will enable quicker sample reporting times and reduce costs by limiting personnel hours dedicated to bench chemistry. Additional benefits may include lower and more consistent blank levels for $\mathrm{U}$ and $\mathrm{Pu}$ and the ability to achieve cleanroom-level blanks without the infrastructure needs of a certified ISO cleanroom. These goals directly address high-priority Milestones 10.2 and 10.3 in the IAEA Long-Term R\&D Plan (STR-375) ${ }^{3}$ by developing new technologies and techniques that will improve the NWALs' ability to provide analytical services to IAEA. By supporting STR-375, this work also addresses the short-term needs described in the Development and Implementation Support Programme for Nuclear Verification 2016-2017 (STR-382). ${ }^{4}$ Specifically, transfer of automated COTS technology to NWAL member laboratories supports SGAS-003, "Analysis Support and NWAL Coordination" and especially the top priority to "Ensure efficient and effective operation of the NWAL." 4

To this end, Oak Ridge National Laboratory (ORNL) worked with Elemental Scientific Inc. (ESI) to customize ESI's COTS sample preparation platform prepFAST-MC. ${ }^{5}$ The original prototype, dubbed the prepFAST-MC2, was installed at ORNL in FY 2016. A second-generation model, the prepFAST-SR, was built by ESI and installed at ORNL in FY17. Both systems closely mirror the manual ORNL NWAL chemistry but use automation to perform chemical separations in unattended, overnight operation. The initial work has been described in more detail previously ${ }^{6-8}$; those results are summarized here, and new data are added where available. Specifically, ORNL has documented significant labor savings using this equipment without any associated impact upon final data quality. As hoped, the blank levels achieved with the system point to its potential to operate as a portable cleanroom in laboratories lacking that infrastructure. Finally, ORNL has evaluated additional COTS technologies to enable efficiencies in other parts of the chemical processing of environmental swipe samples, which are also briefly described herein.

\subsection{DESIGN OF THE PREPFAST-MC2}

In December of 2015, ORNL personnel traveled to ESI headquarters in Omaha, Nebraska, to meet with collaborators Paul Field and Hwan Kim. At this initial meeting, the specific ORNL NWAL chemical purification procedures were shared with ESI; and designs were made to customize the existing ESI product line, the prepFAST-MC, to the specific application of bulk environmental $\mathrm{U}$ and $\mathrm{Pu}$ separations.

The ESI prepFAST-MC system is constructed with a proprietary assembly of valves and pumps that control sample flow throughout the process. This system has a well-documented performance record for similar types of separations using Eichrom resins. An ESI prepFAST-MC installed in a university laboratory demonstrated extremely high chemical recovery (98\%) for 26 consecutive U samples on the same column. Greater than $99.999 \%$ of major matrix contaminants, such as $\mathrm{Na}, \mathrm{Mg}, \mathrm{Al}, \mathrm{Ca}$, and Fe, were successfully removed from the final fraction. A U reference material processed through the system concurrently with samples of natural $\mathrm{U}$ and then analyzed by MC-ICP-MS showed external precision for the measurement of ${ }^{238} \mathrm{U} / 235 \mathrm{U}$ of $0.03 \% .^{5}$

However, the simultaneous separation of both $\mathrm{U}$ and $\mathrm{Pu}$ from the same sample had not been demonstrated. Doing so required two different Eichrom resins, TEVA for Pu recovery and UTEVA for U recovery, in two sequential columns. Moreover, testing at ORNL on the reuse of the TEVA resin showed that recovery of $\mathrm{Pu}$ dropped significantly with multiple uses. Issues associated with the reuse of the 
TEVA resin, along with quality assurance concerns about the reuse of the UTEVA resin for multiple samples, led to the decision to automate the packing and unpacking of the columns with fresh resin for every sample.

\subsection{INSTALLATION OF THE PREPFAST-MC2 SYSTEM AT ORNL}

The newly designed ESI prepFAST-MC2 was delivered in March 2016; it is shown in Figure 1. ESI provided on-site support for the installation, which was originally done in an ISO class 5 cleanroom in the Ultra-Trace Forensic Science Center located at ORNL. Eventually, it was moved to a different, noncleanroom laboratory in the same building, which is where most of the testing described in this section took place. The system was designed to closely mirror the ORNL NWAL chemistry procedure but was modified from the fully COTS prepFAST-MC to automatically pack and unpack both the TEVA and UTEVA columns with fresh resin for each sample.

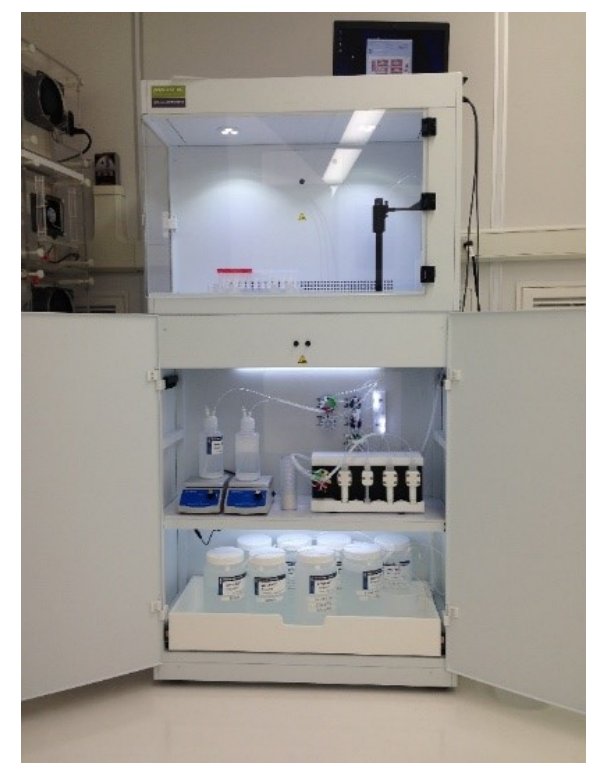

Figure 1. Installation of the prepFAST-MC2 at ORNL.

The system is appropriate for installation in a cleanroom environment (but a cleanroom is not required). Much of the frame is plastic, and any exposed metal is powder coated to prevent metal particles from being released into the laboratory or system. All the reagents are held in plastic bottles on a retractable shelf in the bottom of the cabinet. The shelf and cabinet together serve as secondary containment for the acids used. The resins are contained in bottles on the middle shelf of the cabinet and are placed on stir plates that turn while the system is operating, ensuring homogenization of the resin/acid mixture. The laboratory infrastructure requirements for the system are minimal and are listed in the Pre-Installation Guide provided by ESI. Briefly, the requirements are as follows:

- Space: $826 \mathrm{~mm} \mathrm{~L} \times 430 \mathrm{~mm} \mathrm{~W} \times 1625 \mathrm{~mm} \mathrm{H}$ (from the floor)

- Power outlet within $3 \mathrm{~m}$ of instrument $(120 \mathrm{~V} / 60 \mathrm{~Hz})$

- Exhaust with $69 \mathrm{~mm}$ ID to fit the back panel and a flow rate of 40 cubic feet per minute

- 5 bar of gas pressure (Ar or $\mathrm{N}_{2}$ )

Ultrapure reagents, including acids and American Society for Testing and Materials (ASTM) Type I $(18.2 \mathrm{M} \Omega$ ) water, are strongly recommended. Additionally, the following are specifications for the resins 
used by the system; the recommendation is to have at least one $100 \mathrm{~g}$ bottle of each resin on hand for installation.

- UTEVA resin: Eichrom; 50-100 $\mu \mathrm{m}$; part no. UT-B100-S

- TEVA resin: Eichrom; 50-100 $\mu \mathrm{m}$; part no. TE-B100-S

\subsection{OVERVIEW OF THE PREPFAST-MC2 SYSTEM}

Figure 2 shows the valve assembly of the prepFAST-MC2 system. Samples are introduced via the probe, which also serves to dispense separated sample aliquots into specified vials after column purification. The system is driven by four syringe pumps that are integrated with the valves (not shown). The V9 valve on the top left is responsible for loading and unloading the resins into the columns, while the V9 valve on the bottom right dispenses the appropriate reagents to the columns. Port M8 (bottom left) is connected to the compressed gas line that is used to unpack the spent resin from the column after a sample separation. Port V1 P7 (top right) loads resins, reagents, and the sample to the TEVA column, while V2 P7 (middle right) loads to the UTEVA column. The M10 valve on the syringe pump (not shown) loads the sample and reagents on a loop before they are put onto the packed column. The whole sample line, including the loop, is closed, so that the sample contacts only Teflon tubing, helping to minimize environmental contamination even if the system is not located in a cleanroom. Additionally, when a reagent or sample is loaded onto the loop, it is pushed by an air bubble rather than the next reagent. This liquid/air interface prevents mixing of different reagents with each other and/or the sample as multiple solution matrices are pumped through the same lines.

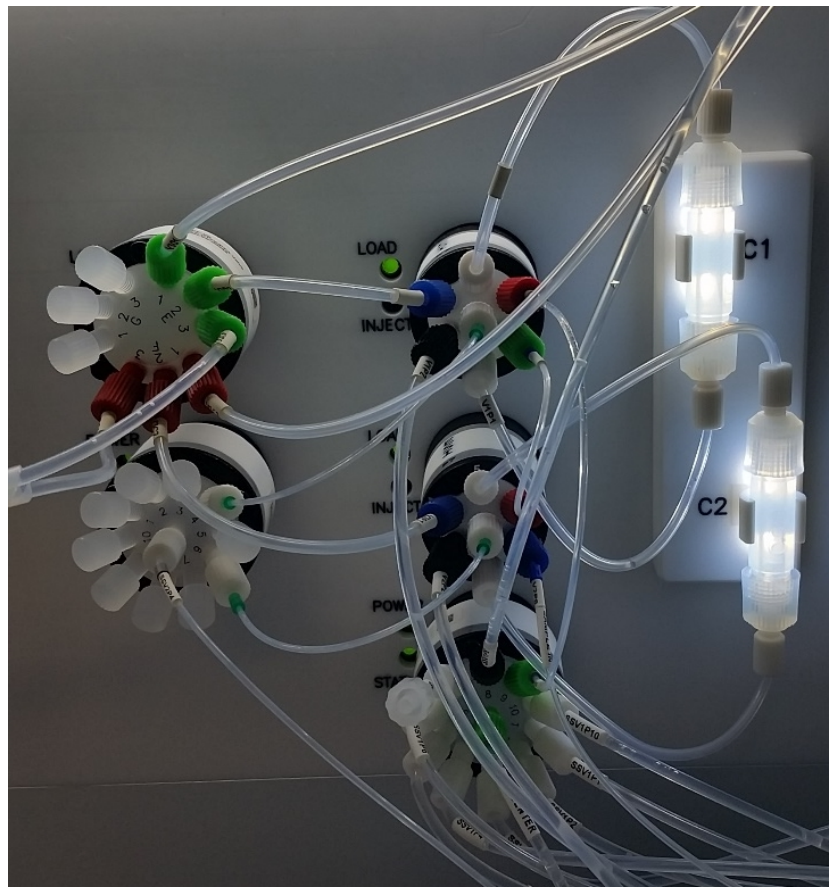

Figure 2. ESI prepFAST-MC2 valve assembly.

The entire assembly is controlled by a laptop computer (provided by ESI) that runs the commercial ESI SC software. The chemistry method employed on the prepFAST-MC2 is "programmed" through the software. Most variables can be easily adjusted by modifying the separation program being used. This modification includes parameters such as reagent volumes and flow rates. Additionally, the software interface specifies the locations of the samples and defines where separated aliquots are to be dispensed. 
This can be combined with an optional bar code reader to track individual samples via a bar code marking molded into the vial. The reader adds a layer of transcription protection from a sample tracking and chainof-custody point of view. Additionally, it allows the system to check for the presence of the appropriate vial at each location in the sample tray before dispensing an aliquot, limiting the potential for loss of sample due to human error in the event vials are misloaded.

\subsection{INSTALLATION OF THE NEW PREPFAST-SR SYSTEM AT ORNL}

During the initial studies in FY16 with the original prepFAST-MC2 system, ORNL staff worked in collaboration with ESI to determine ways to improve the prep $F A S T$-MC2. The new system incorporates upgrades to the valve assembly, case design, and autosampler, including a bar code reader for sample tracking. The extent of the upgrades prompted ESI to also upgrade the name; the new equipment is called the prepFAST-SR. Two new prepFAST-SR systems were procured at the end of FY17. ESI provided onsite support for the installation in the Ultra-Trace Forensic Science Center located at ORNL. One installed prepFAST-SR is shown in Figure 3.

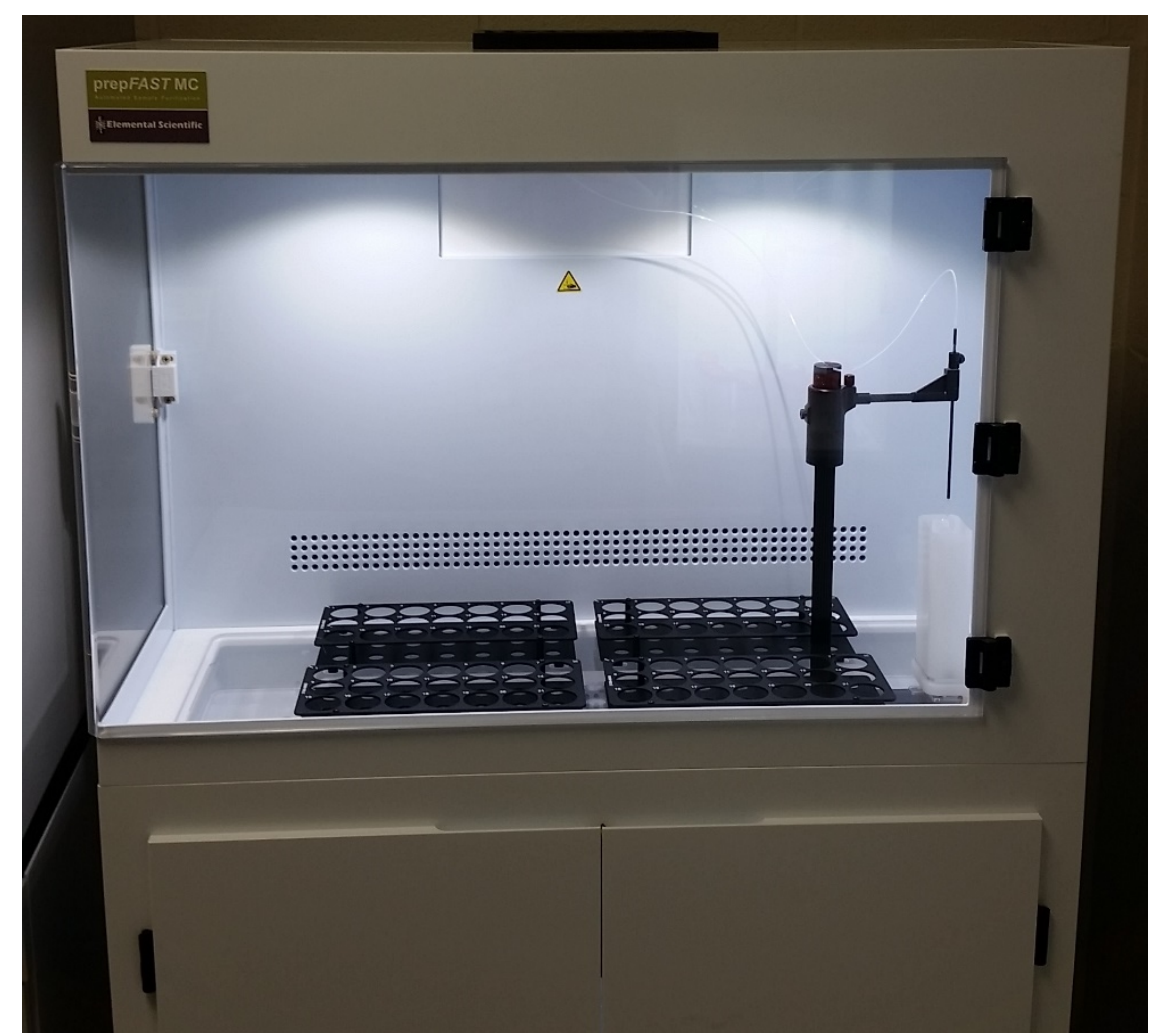

Figure 3. Installation of the new prepFAST-SR at ORNL.

\subsection{OVERVIEW OF THE NEW PREPFAST-SR SYSTEM}

The newly designed prepFAST-SR was installed in August 2017, with the help of ESI representatives. Initial quality control tests by ESI were successful and demonstrated the functionality of the syringe pumps and autosampler. Overall, the operation of the prepFAST-SR is similar to that of its predecessor, the prep $F A S T$-MC2 ${ }^{6-7}$ Updates to the new prep $F A S T$-SR, highlighted in Figure 4, include a new plastic enclosure with a minimal amount of exposed metal. The new enclosure also includes an ultra-low particulate air (ULPA) filter at the top to provide filtered air in the autosampler region (Figure 4A). In the lower cabinet, the valve assembly (Figure 4B) and column design (Figure 4C) have been updated to allow 
for faster packing and unpacking of the bulk resin. The resin loops allow for the resin to be individually preloaded through the loops at a significantly faster flow rate. The additional ports at the top of the columns allow for a flow of acid solution to help expel loose resin during unpacking. ESI has added additional ventilation holes in the autosampler region and changed the ventilation of the lower cabinet to reduce the buildup of acid fumes. Lights in the upper and lower cabinet region have been replaced with brighter LED lights, enabling better viewing of samples.

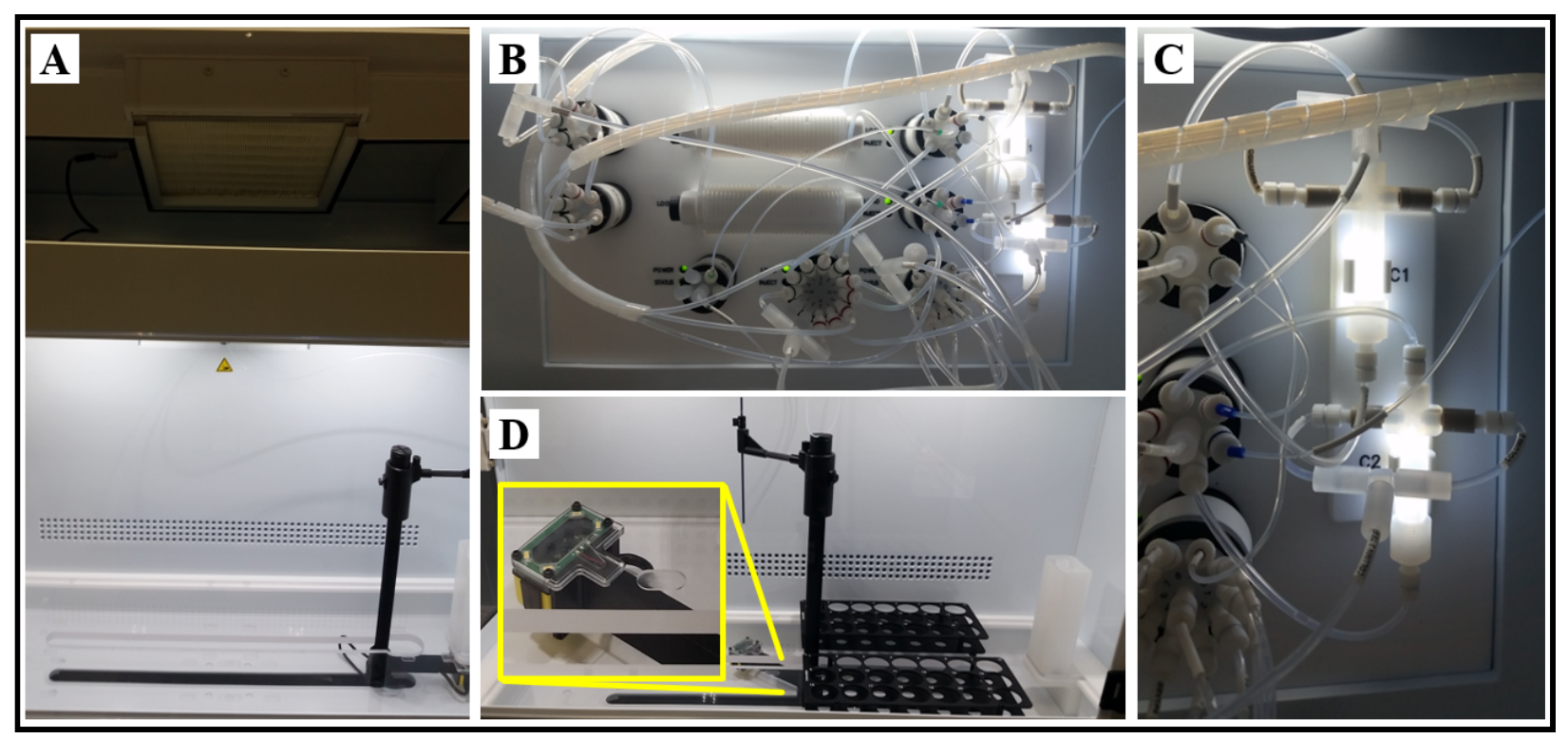

Figure 4. Highlighted updates to the prepFAST-SR: (A) ULPA filter at the top of the new enclosure; (B) updated valve assembly; (C) updated PFA columns; (D) bar code reader with specialized racks.

The new system is controlled by a laptop computer (provided by ESI) that runs an updated version of the commercial ESI SC software. The chemistry methods employed on the prepFAST-SR are controlled and programmed through the software similarly to control of the prepFAST-MC2. The updated software allows the user to adjust designated sub-method parameters (e.g., sample load volume, sample location) from the main program window.

\subsection{BAR CODE READER}

The prepFAST-SR comes equipped with a bar code reader (Figure 4D) to track individual samples via a bar code marking molded into the vial or a lab-made QR code sticker. The reader adds a layer of transcription protection from a sample tracking and chain-of-custody point of view. Additionally, it allows the system to check for the presence of the appropriate vial at each location in the sample tray before dispensing an aliquot, limiting the potential for loss of samples due to human error in the event of misloading of vials. Both of the prepFAST-SR units at ORNL are equipped with bar code readers. However, ESI has not fully incorporated the bar code reader into the newest version of the software, so this feature has not yet been tested by ORNL.

\subsection{OVERVIEW OF THE EVAPOCLEAN SYSTEM}

The EvapoClean from Analab, a fully COTS sub-boiling distillation apparatus, is pictured in Figure 5. It is a six-port vertical hot plate, with a programmable timer, that can distill acids from individual samples, 
each in a completely sealed fluoropolymer environment. The acid matrix of the sample is evaporated and then condensed into a separate vial while the analytes of interest (i.e., actinides in a sample) remain in the original vial, as shown in Figure 6A. The sealed environment limits the exposure of the samples to laboratory air, which enables acid dry-down steps (or matrix conversions) to move out of a cleanroom and into a traditional chemical laboratory. An additional benefit of the equipment is that it can simultaneously be used to reflux acid into labware (via the ports on top of the unit), either to clean new vials or to acid leach previously used vials for reuse (Figure 6B). The dual use of the EvapoClean enables both labware cleaning and sample dry-down to occur outside a cleanroom. This allows it to pair nicely with the prepFAST-SR for installation in a laboratory without cleanroom infrastructure, as sample dry-down and leaching labware are both critical steps for processing low-level environmental samples.

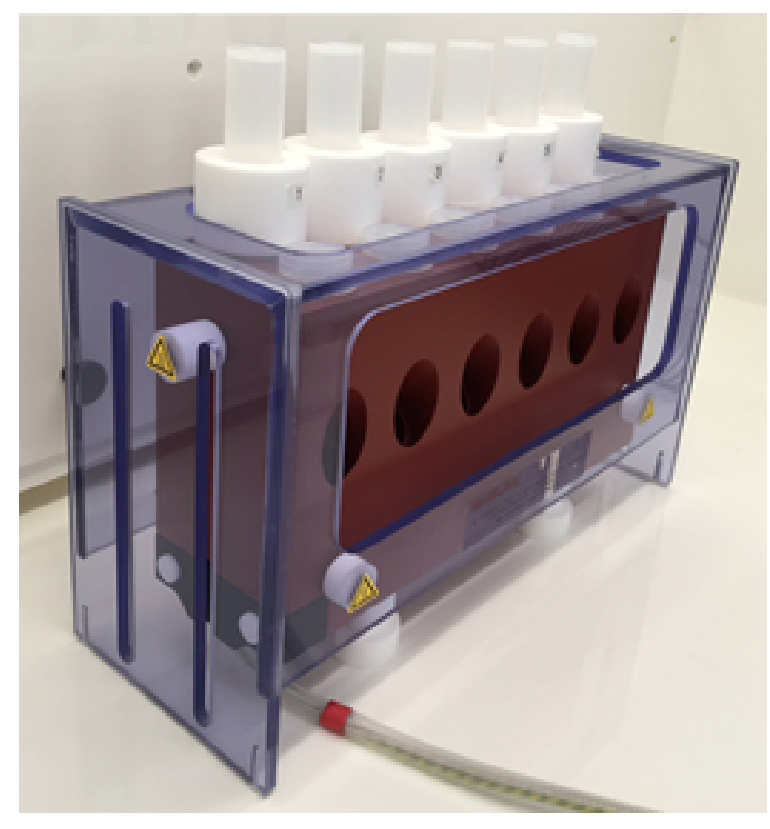

Figure 5. The Analab EvapoClean installed in a chemical hood at ORNL. 


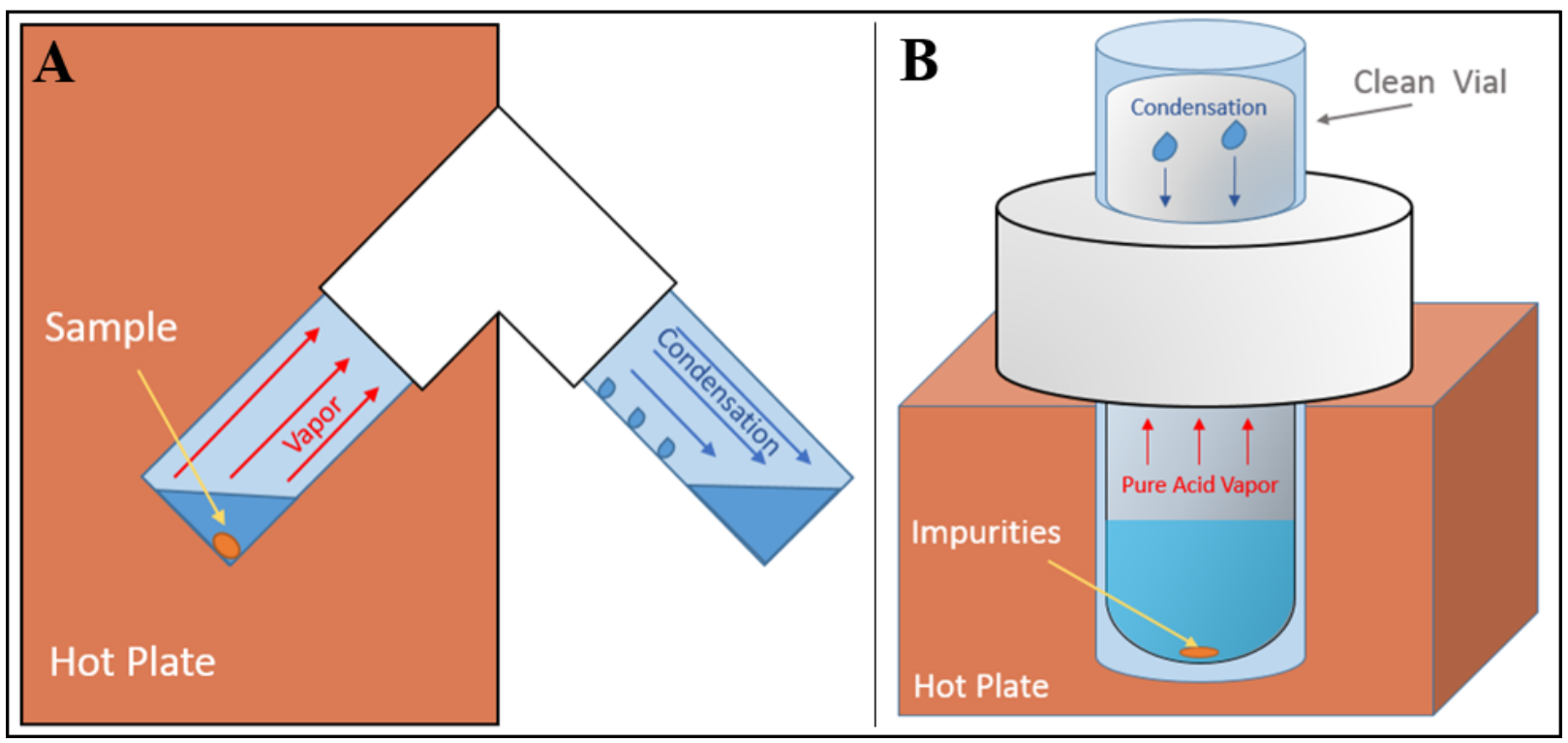

Figure 6. Distillation and matrix reduction setup (A) and leaching setup (B) for the EvapoClean system.

\section{EXPERIMENTAL METHODS}

\subsection{REAGENTS AND STANDARDS}

Only ultrapure reagents were used, with low trace metal content the major consideration in reagent selection. Optima grade $\mathrm{HNO}_{3}, \mathrm{HCl}$, and $\mathrm{HF}$ were purchased through Fisher Scientific and used without further purification. $\mathrm{NaNO}_{2}$ (ACS, 95\% min) and $\mathrm{FeSO}_{4}$ Puratronic 99.999\% (metals basis) were purchased through Alfa Aesar and used without further purification. ASTM Type I (18.2 M $\Omega$ ) water was generated with a Thermo Scientific Barnstead GenPure Pro Water Purification System. Single element standards of $\mathrm{Hg}, \mathrm{Ru}, \mathrm{Au}, \mathrm{Tl}, \mathrm{Os}, \mathrm{Pt}, \mathrm{Zr}, \mathrm{Mo}, \mathrm{Bi}, \mathrm{W}, \mathrm{Pb}$ and Th were purchased from High Purity Standards and used without further purification. Bulk TEVA-resin and UTEVA-resin $(50-100 \mu \mathrm{m}$ particle size) were purchased from Eichrom Industries Inc. Certified Reference Materials (CRMs) for U and $\mathrm{Pu}$ were purchased from the New Brunswick Laboratory (NBL-137, Pu) or the Institute for Reference Materials and Measurements (IRMM-183, U; IRMM-57, ${ }^{233} \mathrm{U}$; IRMM-82, Pu), now the Joint Research Center of the European Commission. An internal ORNL solution of high-purity ${ }^{244} \mathrm{Pu}$ (RAL 22) was used as an isotope dilution spike to determine sample Pu recovery. Its concentration was determined relative to National Institute of Standards and Technology (NIST) Standard Reference Material (SRM) 4330C. All labware was acid leached in $6 \mathrm{M} \mathrm{HCl}, 8 \mathrm{M} \mathrm{HNO}_{3}$, and $18.2 \mathrm{M} \Omega \mathrm{H}_{2} \mathrm{O}$ before use.

\subsection{INSTRUMENTATION}

All mass spectrometric data presented in this report were collected on either an high-resolution inductively coupled plasma mass spectrometer (HR-ICP-MS) or an MC-ICP-MS. A ThermoScientific Element II (Bremen, Germany) was used for all HR-ICP-MS measurements. The Element II is a singlecollector magnetic sector mass spectrometer typically used for elemental analysis. It works by quickly scanning the magnetic field to direct ions sequentially onto the detector. The Element II was used during the column calibration step to quickly scan column elution fractions for both $\mathrm{U}$ and $\mathrm{Pu}$ to verify separation and approximate the recovery. 
A ThermoScientific Neptune Plus (Bremen, Germany) was used for all MC-ICP-MS measurements. The Neptune Plus is used for ORNL NWAL analysis of both $\mathrm{U}$ and $\mathrm{Pu}$ isotope ratio measurements and was used in this study to characterize the mixed CRM samples that were separated on the ESI system. The MC-ICP-MS obtains highly accurate and precise isotope ratio measurements by monitoring all isotopes of $\mathrm{U}$ or $\mathrm{Pu}$ simultaneously on different detectors. Uranium samples in the nanogram range are typically measured using faraday cup detectors, whereas the much smaller Pu samples (picograms) are measured using multiple ion counting detectors. Because of the mass differences between $\mathrm{U}$ and $\mathrm{Pu}$, as well as isobaric interferences such as ${ }^{238} \mathrm{U}$ and ${ }^{238} \mathrm{Pu}, \mathrm{U}$ and $\mathrm{Pu}$ are measured in separate, purified aliquots during different analytical sessions.

Scanning electron microscope (SEM) images were taken on a FEI Phenom operating at $5 \mathrm{kV}$. The electron source was a tungsten emitter. The samples were affixed to an SEM stub with a carbonconductive tab and then imaged at 500× magnification. Multiple image locations were selected at random on each sample and a representative image chosen.

\subsection{GENERAL RESIN PREPARATION}

TEVA resin $(50-100 \mu \mathrm{m}, 10 \mathrm{~mL} ; 4.00 \pm 0.04 \mathrm{~g})$ in a $10 \mathrm{~mL}$ disposable column was preconditioned with $15 \mathrm{~mL}$ of $3 \mathrm{M} \mathrm{HNO}_{3}$ via vacuum filtration and allowed to air dry for $30 \mathrm{~s}$. The TEVA resin was then transferred from the disposable column to its ESI bottle using $3 \mathrm{M} \mathrm{HNO}_{3}(50 \mathrm{~mL}, 55.00 \pm 0.55 \mathrm{~g})$ to yield a 1:5 v:v resin:3 $\mathrm{M} \mathrm{HNO}_{3}$ slurry. UTEVA resin $(50-100 \mu \mathrm{m}, 10 \mathrm{~mL} ; 4.00 \pm 0.04 \mathrm{~g})$ in a $10 \mathrm{~mL}$ disposable column was preconditioned with $15 \mathrm{~mL}$ of $0.01 \mathrm{M} \mathrm{HNO}_{3}$ followed by $5 \mathrm{~mL}$ of $3 \mathrm{M} \mathrm{HNO}_{3}$ via vacuum filtration and allowed to air dry for $30 \mathrm{~s}$. The UTEVA resin was then transferred from the disposable column to its designated ESI bottle using $3 \mathrm{M} \mathrm{HNO}_{3}(50 \mathrm{~mL}, 55.00 \pm 0.55 \mathrm{~g})$ to yield a 1:5 v:v resin:3 M $\mathrm{HNO}_{3}$ slurry. Resin slurries were then either stirred constantly (prepFAST-MC2) or only during column packing (prepFAST-SR) to ensure slurry homogeneity within the bottles.

\subsection{GENERAL SAMPLE PREPARATION}

Samples were prepared in an ISO class 5 or 6 cleanroom, in $3 \mathrm{M} \mathrm{HNO}_{3}$ in leached perfluoroalkoxy alkane (PFA) vials. Samples examined on the automated platforms have been previously described. ${ }^{9}$ Briefly, they included reagent blanks, ashed $4 \times 4$ in. $^{2}$ cotton swipes (TexSwipe TX 304, Lot L308AD), actinide CRMs, and solutions mixed with metals that may cause molecular interferences in the mass spectrometer. Isotope dilution mass spectroscopy (IDMS) was used to quantify the actinide content using RAL 22 $\left({ }^{244} \mathrm{Pu}\right)$ and/or IRMM-57 $\left({ }^{233} \mathrm{U}\right)$. CRM samples were made using NBL 137 and/or IRMM 183 with final concentrations of $0.05-151 \mathrm{pg} / \mathrm{g}$-solution and 1.5-165 ng/g-solution for Pu and U, respectively. Metalcontaminated samples were prepared using single element standards in $3 \mathrm{M} \mathrm{HNO}_{3}$ following the guidelines outlined in Table 1. Samples were prepared by adding $1 \mathrm{~mL}$ of this working solution to either $3 \mathrm{M} \mathrm{HNO}_{3}$ (blank samples) or U/Pu samples.

Table 1. Metal interference stock solution volumes.

\begin{tabular}{cccc}
\hline Element(s) & $\begin{array}{c}\text { Stock concentration } \\
(\boldsymbol{\mu} \mathbf{g} / \mathbf{m L})\end{array}$ & $\begin{array}{c}\text { Volume added } \\
(\mathbf{m L})\end{array}$ & $\begin{array}{c}\text { Final concentration } \\
(\boldsymbol{\mu g} / \mathbf{m L})\end{array}$ \\
\hline $\mathbf{T l}, \mathbf{H g}, \mathbf{R u}, \mathbf{A u}, \mathbf{P t}, \mathbf{O s}$ & 10.00 & 0.02 & 0.01 \\
$\mathbf{Z r}, \mathbf{B i}, \mathbf{M o}, \mathbf{W}$ & 1000 & 0.02 & 1.00 \\
$\mathbf{T h}$ & 10.00 & 10.0 & 5.00 \\
$\mathbf{P b}$ & 1000 & 0.20 & 10.0 \\
\hline
\end{tabular}


The valence state of the $\mathrm{Pu}$ in all samples and blanks was adjusted to $\mathrm{Pu}(\mathrm{IV})$ by adding $\mathrm{FeSO}_{4}(0.2 \mathrm{~mL}$, $1.7 \mathrm{M})$. The vial was capped and swirled to promote mixing. After approximately $5 \mathrm{~min}$, a color change from clear to green and back to clear occurred; $\mathrm{NaNO}_{2}(0.4 \mathrm{~mL}, 3.0 \mathrm{M})$ was then added, and the sample was mixed and allowed to degas for $15 \mathrm{~min}$ before column separation. Final separated aliquots were dried down for matrix reduction and treated with $8 \mathrm{M} \mathrm{HNO}_{3}$ and $\mathrm{H}_{2} \mathrm{O}_{2}(30 \%)$ to destroy column organics. Final fractions were reconstituted in $2 \% \mathrm{HNO}_{3}$ before $\mathrm{MS}$ analysis.

\subsection{ORIGINAL PREPFAST-MC2 GENERAL EXPERIMENTAL DETAILS}

\subsubsection{Initial Column Calibration}

Solutions of IRMM $183(5 \mathrm{ng})$ and NBL 137 (2 pg) were used to make individual samples in $3 \mathrm{M} \mathrm{HNO}_{3}$. The samples were individually processed through the ESI prepFAST-MC2 system in column calibration mode, and each $1 \mathrm{~mL}$ eluent fraction was collected for initial calibration of the columns. A mixed U/Pu sample was made with the same concentrations of IRMM 183 and NBL 137 and separated on the system using the same method.

\subsubsection{Column Packing and Unpacking Reproducibility}

Packing tests on the prepFAST-MC2 were conducted using two $1 \mathrm{~mL}$ Teflon columns $(\mathrm{C} 1$ and $\mathrm{C} 2)$ that were packed with TEVA and UTEVA, respectively, over the duration of the trials. Fresh resin slurries were made in a 1:5 v:v ratio with $3 \mathrm{M} \mathrm{HNO}_{3}$ daily after preconditioning. Unpacked resin was collected in disposable columns, vacuum filtered, air dried for $10 \mathrm{~min}$, and then weighed. Experiments were conducted over the course of several days.

\subsubsection{Packing Method}

The resin packing method is outlined in

Table 2. To summarize, the columns are rinsed with water and the syringes are filled before the resin is primed, without entering the columns. Extra resin in the line and any liquid in the columns is then purged to waste. The loop is filled with air, and the columns are packed simultaneously with resin. Once the columns are full, the resin lines between the valves are purged of any residual resin and the columns are then purged with air sequentially $(\mathrm{C} 1$ then $\mathrm{C} 2)$.

Table 2. Resin packing method.

\begin{tabular}{cl}
\hline Step No. & \multicolumn{1}{c}{ Description: reagent (flow rate) } \\
\hline $\mathbf{1}$ & Rinse columns: $12 \mathrm{~mL}$ water $(10 \mathrm{~mL} / \mathrm{min})$ and reset syringes \\
$\mathbf{2}$ & Prime resin lines: $\mathrm{C} 1-1.55 \mathrm{~mL}, \mathrm{C} 2-1.35 \mathrm{~mL}(2 \mathrm{~mL} / \mathrm{min})$ \\
$\mathbf{3}$ & Purge residual resin: $7 \mathrm{~mL}$ water $(20 \mathrm{~mL} / \mathrm{min})$ and fill loop with air \\
$\mathbf{4}$ & Pack columns: $\mathrm{C} 1$ and $\mathrm{C} 24.25 \mathrm{~mL}$ resin slurry $(0.85 \mathrm{~mL} / \mathrm{min})$ \\
$\mathbf{5}$ & Purge excess resin: $5 \mathrm{~mL}$ water $(20 \mathrm{~mL} / \mathrm{min})$ \\
$\mathbf{6 a}$ & Air purge $\mathrm{C} 1$ column $(10 \mathrm{sec})$ \\
$\mathbf{6 b}$ & Air purge $\mathrm{C} 2$ column $(10 \mathrm{sec})$ \\
\hline
\end{tabular}

\subsubsection{Unpacking Method}

The unpacking methods for the columns are outlined in Table 3. They are identical except for the first step and occur sequentially, with the $\mathrm{C} 2$ column unpacking first followed by the $\mathrm{C} 1$ column. Initially $\mathrm{C} 2$ 
is blown out with compressed $\mathrm{N}_{2}$ gas and then rinsed with $5 \% \mathrm{HNO}_{3}$ four times, whereas $\mathrm{C} 1$ is rinsed with $5 \% \mathrm{HNO}_{3}$ initially and then blown out with $\mathrm{N}_{2}$. The first rinse is dispensed slowly while $\mathrm{N}_{2}$ is flowing to encourage vigorous movement of the $\mathrm{HNO}_{3}$ within the column to expel all resin material. The next three rinses fill the column and then expel all liquid with $\mathrm{N}_{2}$ before flushing the column again. Finally, the resin in the main resin line is purged back to the resin bottle with $5 \% \mathrm{HNO}_{3}$.

Table 3. Resin unpacking method.

\begin{tabular}{|c|c|}
\hline Step No. & Description: reagent (flow rate) \\
\hline 1 & Purge: $\mathrm{C} 2$ resin with $\mathrm{N}_{2} ; \mathrm{C} 1$ resin with $2 \mathrm{~mL} 5 \% \mathrm{HNO}_{3}(2 \mathrm{~mL} / \mathrm{min})$ \\
\hline $2 \mathbf{a}$ & Vigorous wash: $12 \mathrm{~mL} 5 \% \mathrm{HNO}_{3}(5 \mathrm{~mL} / \mathrm{min})$ with $\mathrm{N}_{2}$ flow \\
\hline $2 \mathbf{b}$ & Purge residual resin/solution with $\mathrm{N}_{2}$ \\
\hline 3a & Flush column with $12 \mathrm{~mL}$ of $5 \% \mathrm{HNO}_{3}(20 \mathrm{~mL} / \mathrm{min})$ \\
\hline $3 \mathbf{b}$ & Purge solution with $\mathrm{N}_{2}$ \\
\hline $4-5$ & Repeat step 3 twice more ( 3 total) \\
\hline 6 & Resin line purge: $3.7 \mathrm{~mL} 5 \% \mathrm{HNO}_{3}(10 \mathrm{~mL} / \mathrm{min})$ \\
\hline
\end{tabular}

\subsubsection{Separations Chemistry Method}

The separations chemistry method is outlined in Table 4. Briefly, after the columns are packed as described in Table 2, the sample is loaded and flows through the columns ( $\mathrm{C} 1$ to $\mathrm{C} 2)$, which are then sequentially washed with $3 \mathrm{M} \mathrm{HNO}_{3}$. The columns are treated individually with an additional $3 \mathrm{M} \mathrm{HNO}_{3}$ wash. $\mathrm{C} 1$ is rinsed with $\mathrm{HCl}$ to convert the TEVA resin to the chloride form. Next, the $\mathrm{U}$ fraction is eluted, followed by the Pu fraction. Finally, both columns are unpacked as described in Table 3.

Table 4. Method description for the separation of U/Pu with the ESI system.

\begin{tabular}{cl}
\hline Step No. & \multicolumn{1}{c}{ Description: reagent (flow rate) } \\
\hline $\mathbf{1}$ & Pack TEVA $(\mathrm{C} 1)$ and UTEVA $(\mathrm{C} 2)$ resin columns \\
$\mathbf{2}$ & Load sample: $3 \mathrm{~mL}$ of sample $(1 \mathrm{~mL} / \mathrm{min})$ \\
$\mathbf{3}$ & Wash columns $(\mathrm{C} 1$ and $\mathrm{C} 2): 3 \mathrm{~mL}$ of $3 \mathrm{M} \mathrm{HNO}_{3}(2 \mathrm{~mL} / \mathrm{min})$ \\
$\mathbf{4 a}$ & Wash column $\mathrm{C} 1: 3 \mathrm{~mL}$ of $3 \mathrm{M} \mathrm{HNO}_{3}(2 \mathrm{~mL} / \mathrm{min})$ \\
$\mathbf{4 b}$ & Wash column $\mathrm{C} 2: 3 \mathrm{~mL}$ of $3 \mathrm{M} \mathrm{HNO} /(2 \mathrm{~mL} / \mathrm{min})$ \\
$\mathbf{5}$ & Convert to chloride $(\mathrm{C} 1): 2 \mathrm{~mL}$ of $9 \mathrm{M} \mathrm{HCl}(2 \mathrm{~mL} / \mathrm{min})$ \\
$\mathbf{6}$ & Elute $\mathrm{U}(\mathrm{C} 2): 2 \mathrm{~mL}$ of $0.02 \mathrm{M} \mathrm{HNO}{ }^{-}-0.005 \mathrm{M} \mathrm{HF}(1 \mathrm{~mL} / \mathrm{min})$ twice \\
$\mathbf{7}$ & Elute Pu $(\mathrm{C} 1): 4 \mathrm{~mL}$ of $0.1 \mathrm{M} \mathrm{HCl}-0.06 \mathrm{M} \mathrm{HF}(1 \mathrm{~mL} / \mathrm{min})$ twice \\
$\mathbf{8}$ & Unpack UTEVA $(\mathrm{C} 2)$ resin sorbent \\
$\mathbf{9}$ & Unpack TEVA $(\mathrm{C} 1)$ resin sorbent \\
\hline
\end{tabular}

\subsubsection{Archived Swipe Samples}

Archived samples were used for validation of the original prepFAST-MC2 system and methods. For the first sample, $500 \mu \mathrm{L}$ of $3 \mathrm{M} \mathrm{HNO}_{3}$ was added and the sample was then heated overnight at $60{ }^{\circ} \mathrm{C}$. This sample was not spiked before separation. The remaining samples were treated first with small amounts of $\mathrm{HF}$ to yield a final concentration of $\sim 50 \mathrm{mM}$ before being heated at $80^{\circ} \mathrm{C}$ overnight, dried down, and reconstituted in $3 \mathrm{M} \mathrm{HNO}_{3}$. The second set were all spiked with RAL 22 before sample preparation. Blanks (3 $\mathrm{M} \mathrm{HNO}_{3}$ ) and standard solutions (CRM IRMM 183, $5 \mathrm{ng}$; NBL 137, 2 pg) were also prepared. 
The general sample preparation method described in Section 2.4 was followed for each set of samples, standards, and blanks before separation on the original prep $F A S T$-MC2.

\subsection{UPDATED PREPFAST-SR EXPERIMENTAL DETAILS}

\subsubsection{Validation Through CRM Separation}

Samples containing IRMM 183 (5 ng) and NBL 137 (2 pg) in $3 \mathrm{M} \mathrm{HNO}_{3}$, and blank $3 \mathrm{M} \mathrm{HNO}_{3}$, were prepared as described in Section 2.4. Three series of 11 separations per series ( 6 blanks and 5 samples, alternating) were loaded into the ESI software for overnight, unattended, separation on 3 different days on both new prepFAST-SR units for method validation.

\subsubsection{Automated IDMS Spiking}

The new prepFAST-SR system was programmed to perform automated IDMS spiking using $18.2 \mathrm{M} \Omega$ $\mathrm{H}_{2} \mathrm{O}$ at several volumes $(0.10,0.12,1.0,5.0$, and $10.0 \mathrm{~mL})$. Briefly, in this method, the inside and outside of the probe were rinsed twice with $2 \% \mathrm{HNO}_{3}$ in the probe wash stations before the "spike" was loaded. Once the spike was loaded, the outside of the probe was rinsed twice more with $2 \% \mathrm{HNO}_{3}$ in the probe wash stations. The spike was then dispensed into the designated vial. After dispensing, the inside and outside of the probe were again rinsed twice with $2 \% \mathrm{HNO}_{3}$ in the probe wash stations. The mass of the dispensed spike was then manually determined on an analytical balance.

\subsection{COMPARISON WITH ORNL NWAL CHEMISTRY}

Experimentally, the chemistry performed by the automated systems is intentionally very similar to the ORNL NWAL manual chemistry method. Some differences are briefly outlined in Table 5.

Table 5. Chemistry differences in the automated method and ORNL NWAL manual chemistry.

\begin{tabular}{c|cc}
\hline Parameter & Automated method & ORNL NWAL Manual chemistry \\
\hline Column size & $1 \mathrm{~mL}$ & $2 \mathrm{~mL}$ \\
U elution & $4 \mathrm{~mL}$ & $5 \mathrm{~mL}$ \\
Pu elution & $8 \mathrm{~mL}$ & $12 \mathrm{~mL}$ \\
Use of prefilter & No & Yes \\
Pu elution reagent & $0.1 \mathrm{M} \mathrm{HCl}-0.06 \mathrm{M} \mathrm{HF}$ & $0.1 \mathrm{M} \mathrm{HCl}-0.06 \mathrm{M} \mathrm{HF}-0.02 \mathrm{M} \mathrm{NH}_{4} \mathrm{I}$ \\
\hline
\end{tabular}

\subsection{EVALUATION OF ADDITIONAL COTS EQUIPMENT}

\subsubsection{Microwave Digestion of Swipe Samples}

Blank cotton swipes (three) were ashed overnight in separate Pyrex glass tubes using a Thermcraft tube furnace equipped with a Eurotherm 2404 temperature controller. The full furnace program is outlined in Table 6. Briefly, the samples were heated to $600{ }^{\circ} \mathrm{C}$ and then held at $600{ }^{\circ} \mathrm{C}$ for $12 \mathrm{~h}$ before being allowed to cool back to room temperature. The residual ash from the swipes was then transferred to Pyrex CEM microwave vessels using $8 \mathrm{M} \mathrm{HNO}_{3}(5 \mathrm{~mL})$. The samples were microwaved using a Discover SP-D from CEM. The final microwave method is described in Table 7. Briefly, while being stirred at medium speed, the samples were heated for over $4 \mathrm{~min}$ to $200{ }^{\circ} \mathrm{C}$ and then held at $200{ }^{\circ} \mathrm{C}$ for $10 \mathrm{~min}$ before cooling back to room temperature. The pressure maximum was set to 400 pounds per square inch (psi) for venting. After microwave digestion, one of the three samples was transferred to a $15 \mathrm{~mL}$ PFA vial using $18.2 \mathrm{M} \Omega$ $\mathrm{H}_{2} \mathrm{O}(5 \mathrm{~mL})$. IRMM 183 ( $\sim 80 \mathrm{ng}$ total) was added to the sample, followed by $\mathrm{HF}$ (conc. of $1 \mathrm{~mL}$ ). The sample was then dried down on the EvapoClean system at $130{ }^{\circ} \mathrm{C}$ and constituted in $3 \mathrm{M} \mathrm{HNO}_{3}(4 \mathrm{~mL})$ 
before manual separation on a 2 mL UTEVA cartridge, following the ORNL manual chemistry separation standard operating procedure. Briefly, the UTEVA cartridge was pre-cleaned with $0.01 \mathrm{M} \mathrm{HNO}_{3}(3 \mathrm{~mL})$ and $3 \mathrm{M} \mathrm{HNO}_{3}(12 \mathrm{~mL})$. The sample was then loaded onto the column and the vial was rinsed with $3 \mathrm{M}$ $\mathrm{HNO}_{3}(3 \times 1 \mathrm{~mL})$. The UTEVA column was rinsed with an additional $3 \mathrm{M} \mathrm{HNO}_{3}(20 \mathrm{~mL})$ before elution of the $\mathrm{U}$ using $0.02 \mathrm{M} \mathrm{HNO}_{3}-0.05 \mathrm{M} \mathrm{HF}(5.5 \mathrm{~mL})$. The sample was dried down using the EvapoClean system at $130{ }^{\circ} \mathrm{C}$ and resuspended in $2 \% \mathrm{HNO}_{3}(1.5 \mathrm{~mL})$. The sample and distillate $\mathrm{U}$ isotopics were then analyzed via MC-ICP-MS.

Table 6. Furnace program for ashing cotton swipes.

\begin{tabular}{ccccc}
\hline Step & Initial T $\left({ }^{\circ} \mathbf{C}\right)$ & Final T $\left({ }^{\circ} \mathbf{C}\right)$ & $\Delta \mathbf{T}$ rate $\left({ }^{\circ} \mathbf{C} / \mathbf{m i n}\right)$ & Hold time \\
\hline $\mathbf{1}$ & $\mathrm{RT}$ & 100 & 10 & $1 \mathrm{~min}$ \\
$\mathbf{2}$ & 100 & 200 & 7.5 & $20 \mathrm{~min}$ \\
$\mathbf{3}$ & 200 & 300 & 7.5 & $40 \mathrm{~min}$ \\
$\mathbf{4}$ & 300 & 400 & 7.5 & $40 \mathrm{~min}$ \\
$\mathbf{5}$ & 400 & 600 & 5 & $12 \mathrm{~h}$ \\
Cool down & 600 & $\mathrm{RT}$ & 10 & $\mathrm{~N} / \mathrm{A}$ \\
\hline
\end{tabular}

Table 7. ORNL microwave digestion method.

\begin{tabular}{ccccccc}
\hline Stage & Ramp (min) & Pressure (psi) & Temperature $\left({ }^{\circ} \mathbf{C}\right)$ & Hold $(\mathbf{m i n})$ & Power $(\mathbf{W})$ & Stirring \\
\hline 1 & $4: 00$ & 400 & 200 & $10: 00$ & 300 & Medium \\
\hline
\end{tabular}

Additionally, six cotton swipes were sent to CEM for research and development testing on larger CEM microwaves to test complete digestion of swipes without furnace ashing. The report from CEM is attached in Appendix 1.

\subsubsection{Matrix Reduction Using EvapoClean System}

\subsubsection{Reducing Background Counts through Leaching}

A six-position EvapoClean heating block (Figure 5) with an Analab P116 temperature controller was used to leach six new $15 \mathrm{~mL}$ Savillex vials. Each $15 \mathrm{~mL}$ vial was fitted with an adapter, which was connected to a $25 \mathrm{~mL}$ vial placed in the heating block, as shown in Error! Reference source not found.. Each set of vials had $8 \mathrm{M} \mathrm{HNO}_{3}(5 \mathrm{~mL})$ added and were placed in the top of the EvapoClean system. Vials were then heated at $130{ }^{\circ} \mathrm{C}$ for $2 \mathrm{~h}$. The $12 \mathrm{~mL}$ vials were then rinsed three times with $18.2 \mathrm{M} \Omega ~_{2} \mathrm{O}$ and allowed to dry in an ISO class 5 cleanroom. Six additional Savillex vials were subjected to the conventional ORNL cleanroom leaching method (6 M HCl, $8 \mathrm{M} \mathrm{HNO}_{3}, 18.2 \mathrm{M} \Omega \mathrm{H}_{2} \mathrm{O}$ for $16 \mathrm{~h}$ each, with three rinses with $18.2 \mathrm{M} \Omega \mathrm{H}_{2} \mathrm{O}$ between each and at the end), and six new vials were left untreated. After the cleaned vials were dried overnight, $2 \% \mathrm{HNO}_{3}(2 \mathrm{~mL})$ was added to each of the vials (unleached, leached new, and EvapoClean) and they were left to soak for $16 \mathrm{~h}$. The acid was then analyzed via HRICP-MS for ${ }^{232} \mathrm{Th},{ }^{235} \mathrm{U}$, and ${ }^{238} \mathrm{U}$ content. Vials previously used for IRMM $183,{ }^{233} \mathrm{U}(\sim 1 \mathrm{ng})$, NBL 137, or ${ }^{244} \mathrm{Pu}(\sim 2 \mathrm{pg})$ sample analysis were also leached on the EvapoClean system and through conventional leaching methods, as described previously, to evaluate the potential for cleaning and reusing vials. Then $2 \% \mathrm{HNO}_{3}(2 \mathrm{~mL})$ was placed in all vials and allowed to set overnight $(16 \mathrm{~h})$ before analysis via HR-ICPMS. 


\subsubsection{Decreasing Cross-Contamination via Sample Concentration in a Closed Environment}

The same six-position EvapoClean heating block with an Analab P116 temperature controller was used as a small closed distillation apparatus, as shown in Figure 6. A sample solution $(5 \mathrm{~mL})$ containing $0.5 \mathrm{ppb}$ of 40 different elements (Al, Sb, As, Ba, Be, Bi, B, Cd, Ca, Cr, Co, Cu, Ga, Ge, Au, In, Fe, La, Pb, Li, $\mathrm{Mg}, \mathrm{Mn}, \mathrm{Mo}, \mathrm{Ni}, \mathrm{Nb}, \mathrm{Pd}, \mathrm{P}, \mathrm{Pt}, \mathrm{K}, \mathrm{Ag}, \mathrm{Na}, \mathrm{Sr}, \mathrm{Ta}, \mathrm{Tl}, \mathrm{Sn}, \mathrm{Ti}, \mathrm{W}, \mathrm{V}, \mathrm{Zn}$, and $\mathrm{Zr}$ ) in $2 \% \mathrm{HNO}_{3}$ was distilled in a $30 \mathrm{~mL}$ PFA vial. The temperature was decreased over the course of the experiment $(2 \mathrm{~h})$ from 145 to $135^{\circ} \mathrm{C}$ as the sample volume decreased. The residue was resuspended in $2 \% \mathrm{HNO}_{3}(2 \mathrm{~mL})$ for analysis via HR-ICP-MS.

The recoveries of $\mathrm{U}$ and of $\mathrm{Pu}$ were examined separately in a similar fashion. Samples of $\mathrm{U}$ with $5 \mathrm{ng}$ IRMM 183 in $11 \mathrm{~mL}$ of $3.6 \mathrm{M} \mathrm{HNO}_{3}-2.5 \mathrm{M} \mathrm{HF}$ were distillated at temperatures ranging from 110 to $150{ }^{\circ} \mathrm{C}\left(\Delta=10^{\circ} \mathrm{C}\right)$. Distillation time was linked to temperature and ranged from approximately $7 \mathrm{~h}$ at the lower temperature to $2.5 \mathrm{~h}$ at $150{ }^{\circ} \mathrm{C}$. Residues were dissolved in $2 \% \mathrm{HNO}_{3}(2 \mathrm{~mL})$ and analyzed by $\mathrm{HR}-$ ICP-MS and MC-ICP-MS. Recovery of Pu was examined using NBL 137 (2 pg) in $1 \mathrm{~mL}$ of $3 \mathrm{M} \mathrm{HNO}_{3}$. Samples were distilled at $120{ }^{\circ} \mathrm{C}$ for approximately $90 \mathrm{~min}$. Sample residues were dissolved in $2 \% \mathrm{HNO}_{3}$ $(1 \mathrm{~mL})$ and spiked with RAL 22. Sample distillate was transferred to pre-weighed vials and spiked with a similar amount of RAL 22. Samples were then heated on a hot plate at $50{ }^{\circ} \mathrm{C}$ overnight before analysis by MC-ICP-MS. Conventional matrix conversion methods for the sample Pu solution $(1 \mathrm{~mL})$ were also carried out for comparison. Conventionally dried samples were reconstituted with $2 \% \mathrm{HNO}_{3}(1 \mathrm{~mL})$, spiked with RAL 22, and heated overnight at $50{ }^{\circ} \mathrm{C}$ before analysis by MC-ICP-MS.

\section{RESULTS AND DISCUSSION}

\subsection{ORIGINAL PREPFAST-MC2}

\subsubsection{Initial Column Calibration}

Because ESI could not handle Pu at its facility, the column elution profiles were determined at ORNL after installation of the prepFAST-MC2. The calibration of the columns was initially done independently, with a sample containing just U (5 ng, IRMM 183) loaded on the UTEVA column and a sample of just Pu ( $2 \mathrm{pg}$, NBL 137) loaded on the TEVA column. Then, a mixed U/Pu sample was run through the system. The profiles were determined by collecting the entire volume of acid used for the elution in $1 \mathrm{~mL}$ fractions and then analyzing each aliquot for $\mathrm{U}$ and/or Pu by HR-ICP-MS. The process was repeated twice to ensure reproducibility. These full calibration experiments ensure that in the final automated method, the $\mathrm{U}$ and $\mathrm{Pu}$ aliquots taken for analysis contain the entire sample that will elute off the column. They also serve to verify that the $\mathrm{U}$ and $\mathrm{Pu}$ are fully separated from each other in the recovered samples. This study was conducted while the instrument was in an ISO class 5 cleanroom.

Figure 7 shows that the calibrations of Pu and U elution on the TEVA and UTEVA columns, respectively, were reproducibly achieved with high recovery. The figure plots the percentage of the total actinide recovered that is present in each $1 \mathrm{~mL}$ elution fraction. The elution profile of $\mathrm{Pu}(8 \mathrm{~mL})$ is wider than that for $\mathrm{U}(4 \mathrm{~mL})$ but is still reasonably narrow. The total $\mathrm{Pu}$ recovery calculated from the mass spectrometry data for Run 1 was $85 \%$ and Run 2 was $58 \%$, both in the range expected from this separation technique. Total U recovery for both Run 1 and Run 2, calculated from the mass spectrometry data, was better than $99 \%$, with high reproducibility between the replicate analyses. The reduction in the elution volumes versus the manual chemistry represents a time savings that would be realized in the lengthy dry-down step that follows the separation. 


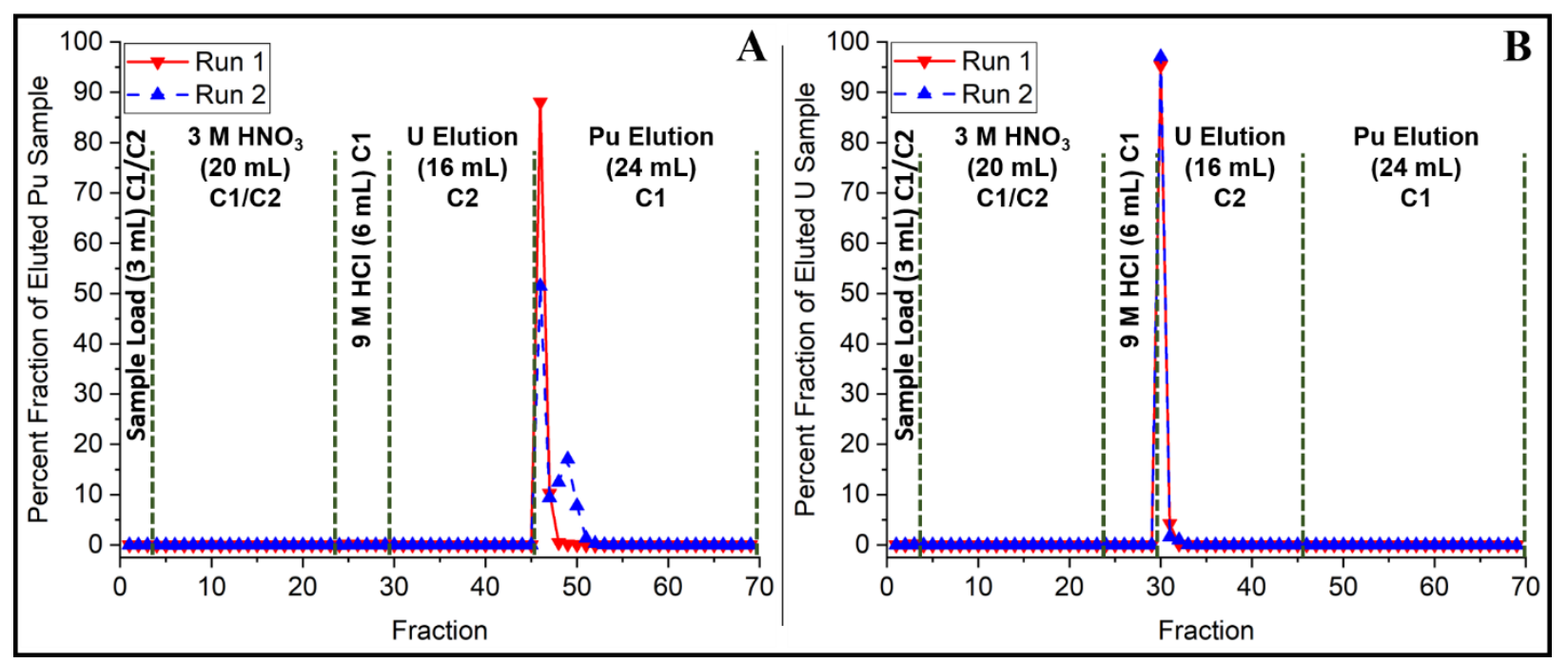

Figure 7. Individual column calibration elution profiles for Pu (A) and U (B) automated separation. ${ }^{9}$

Full system calibration for the separation of a mixed U/Pu sample using both columns was achieved under automated control. A high degree of separation between the elution of $U$ (red downward triangles) and $\mathrm{Pu}$ (blue upward triangles) fractions is shown in Figure 8. The total recovery calculated from the mass spectrometry data was $101 \%$ for $\mathrm{U}$ and $57 \%$ for $\mathrm{Pu}$. Notably, there is no $\mathrm{U}$ present in the Pu fraction, and vice versa. The characterization of these elution profiles with the prepFAST-MC2 running under automated control was critical to establishing the method parameters in the ESI software. Specifically, the wash volumes for the reagents and the elution volumes were optimized using this data.

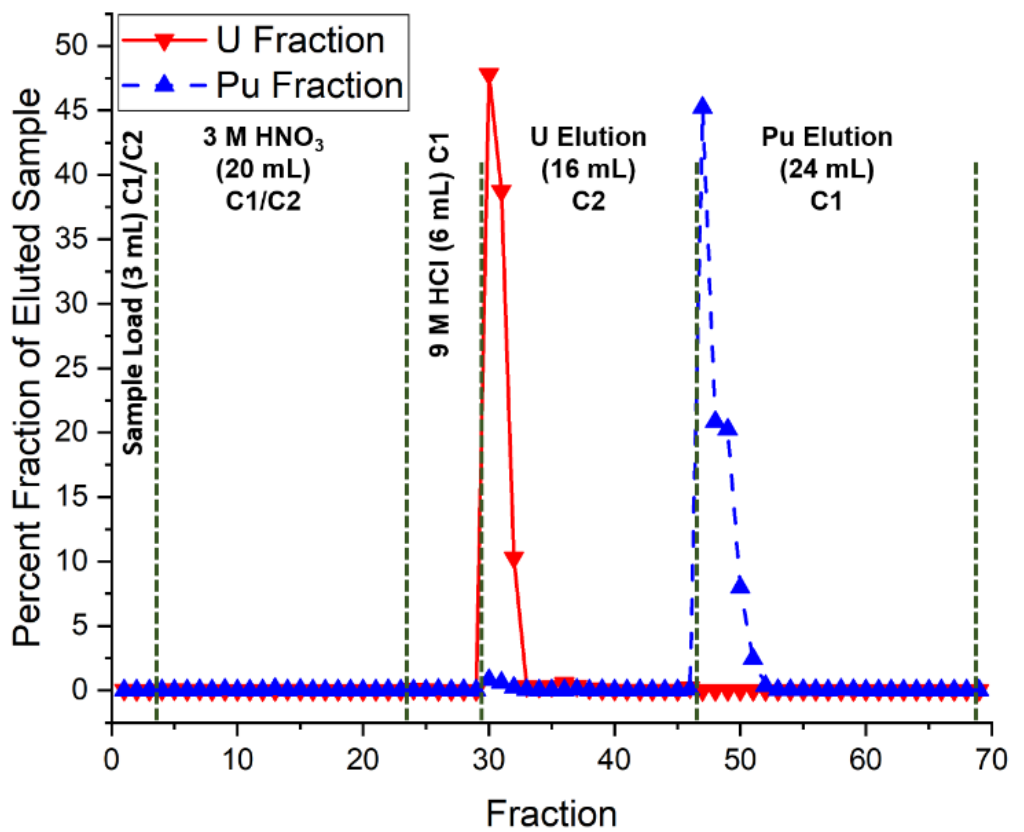

Figure 8. Combined UTEVA and TEVA column calibration runs for $U$ (red) and Pu (blue) separations. The percentage fraction is calculated by dividing the instrument response rate (counts) in each fraction by the sum of the total counts in all the fractions. ${ }^{9}$ 


\subsubsection{Column Packing and Unpacking Reproducibility}

Initial studies of the prepFAST-MC2 resin mass loading yielded large deviations ( $>15 \% \mathrm{RSD})$. Several factors listed in Table 8 contributed to the observed deviations and were sequentially addressed.

Table 8. Problems addressed in achieving reproducible renewable column generation.

\begin{tabular}{|l|l|}
\hline \multicolumn{1}{|c|}{ Problem } & \multicolumn{1}{c|}{ Solution } \\
\hline $\begin{array}{l}\text { Inconsistent pressure during unpacking — decreased column unpacking } \\
\text { efficiency }\end{array}$ & $\begin{array}{l}\text { Replace T-joint gas line with } \\
\text { individual gas lines }\end{array}$ \\
\hline $\begin{array}{l}\text { Backpressure buildup in individual gas lines during unpacking—decreased } \\
\text { column unpacking efficiency }\end{array}$ & $\begin{array}{l}\text { Use smaller internal diameter gas } \\
\text { lines }\end{array}$ \\
\hline Frit blow-out in C1—deformed column cap & Replace column cap \\
\hline $\begin{array}{l}\text { Settling of resin slurry within resin lines leading to columns—inconsistent } \\
\text { column packing }\end{array}$ & $\begin{array}{l}\text { Add resin line prime and purge } \\
\text { steps to method }\end{array}$ \\
\hline $\begin{array}{l}\text { Inhomogeneity within the } 500 \mathrm{~mL} \text { resin slurry bottle—increase in packing } \\
\text { mass over time }\end{array}$ & $\begin{array}{l}\text { Use smaller resin bottle size } \\
(125 \mathrm{~mL})\end{array}$ \\
\hline
\end{tabular}

The resolution of the problems listed in Table 8 decreased the observed daily $(0.556 \pm 0.030 \mathrm{~g}$ and 0.601 $\pm 0.019 \mathrm{~g}$ for $\mathrm{C} 1$ and $\mathrm{C} 2$, respectively) packing deviations to approximately $5 \%$, as seen in Figure 9 . This variability is similar to values quoted by Eichrom for its prepacked columns. Additionally, a decrease was observed in the 3 day $(0.538 \pm 0.037 \mathrm{~g}$ and $0.555 \pm 0.049 \mathrm{~g}$ for $\mathrm{C} 1$ and $\mathrm{C} 2$, respectively) packing deviations. Further improvements may result from more consistent initial resin slurry mixtures.

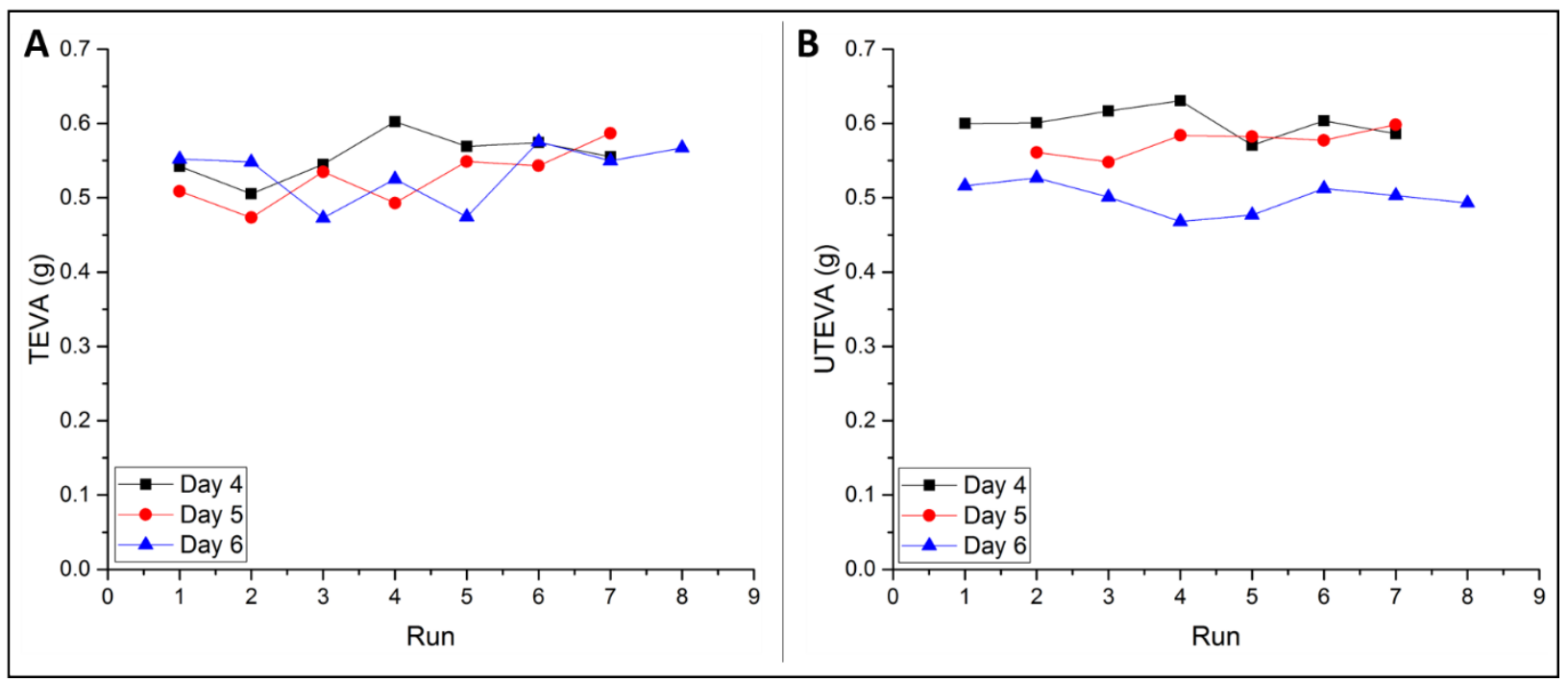

Figure 9. Packing of TEVA (C1) column (A) and UTEVA (C2) column (B) over 3 days using $125 \mathrm{~mL}$ bottles.

\subsubsection{SEM Imaging}

The same column frits were used over the course of the packing/unpacking experiments, as no visual decrease in packing efficiency was observed over 3 days. This was consistent with the initial suggestion 
from ESI personnel that each frit could withstand about 30 pack/unpack cycles. However, to verify that flow through the frits was unimpeded, SEM images of a new frit and used frits were taken for comparison; they demonstrated no resin residue after packing and unpacking experiments.

Separation experiments on mixed U/Pu samples, using the full separation procedure, were started with the intention of using frits for a similar amount of time. However, after 14 total separations over 2 days, a significant amount of resin material remained within column $\mathrm{C} 1$. The frits were removed, and SEM images were captured of an unused control frit (Figure 10-Control), the frit from C1 (Figure 10-A), and the frit from $\mathrm{C} 2$. The used frits from $\mathrm{C} 1$ and $\mathrm{C} 2$ showed significant residual resin compared with the new frit, with approximately $75 \%$ blockage of the $\mathrm{C} 1$ frit. SEM images of the resin slurry after $24 \mathrm{~h}$ of mixing the resin beads within the slurry bottles demonstrated severe breakdown of the resin, whereas freshly made resin slurry demonstrated no breakage. The fresh slurry mixture was then stirred relatively fast and SEM images were taken after 1, 8, 24, and $48 \mathrm{~h}$. Using a second batch of fresh resin slurry, stirring was then slowed by $\sim 15 \%$ of the previous value and SEM imaging was repeated at $1,8,24$, and $48 \mathrm{~h}$. A comparison of the resin breakdown after fast and slow stirring is shown in Figure 11. Separations were continued with slower stirring of the resin slurry and, after 21 separations over 3 days, SEM imaging of the $\mathrm{C} 1$ (Figure 10-B) and C2 frits showed no resin residue. 


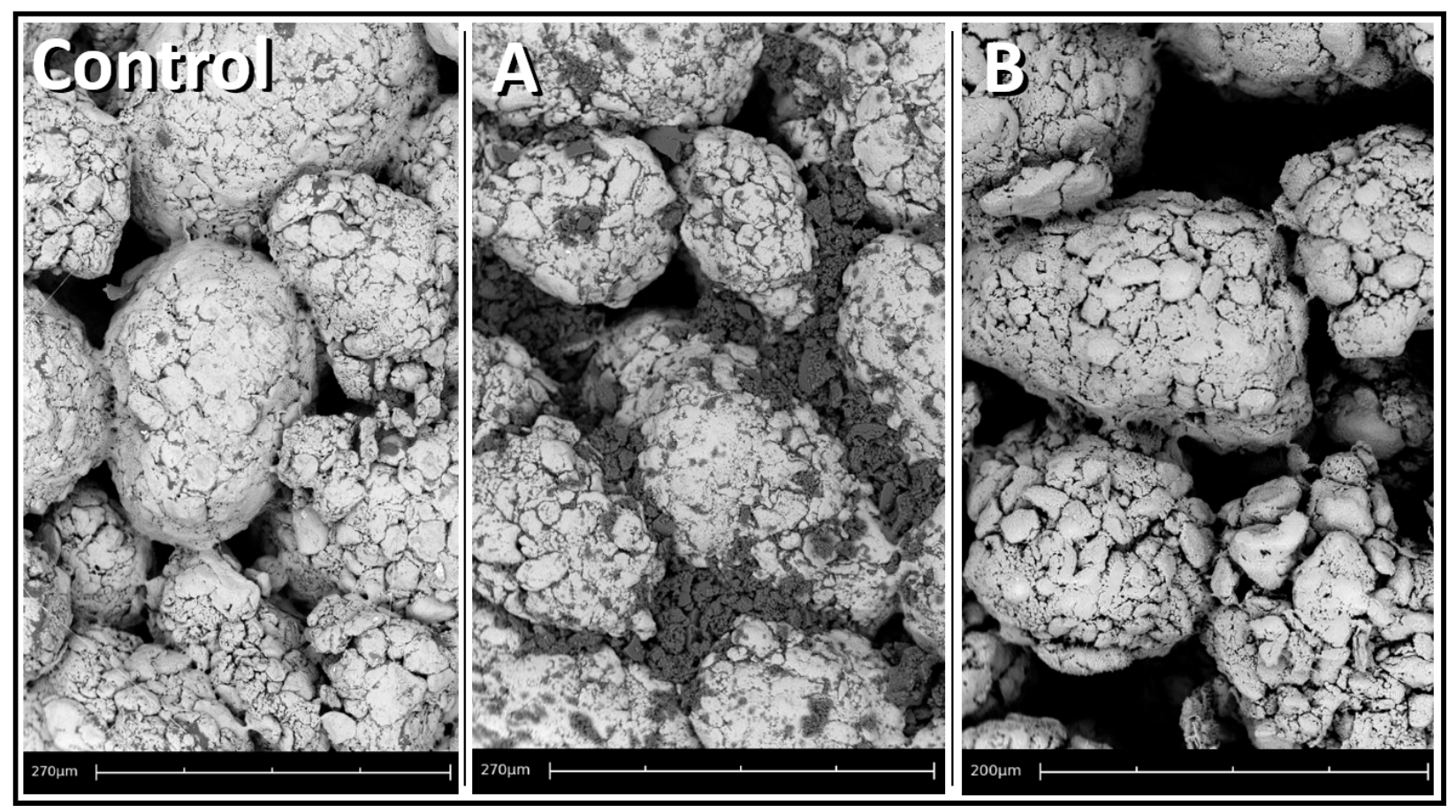

Figure 10. Comparison of SEM images of a new frit (Control), a frit after 14 separations on $\mathrm{C} 1$ with fast resin slurry stirring (A), and a frit after 21 separations on $\mathrm{C1}$ with slow resin slurry stirring (B).

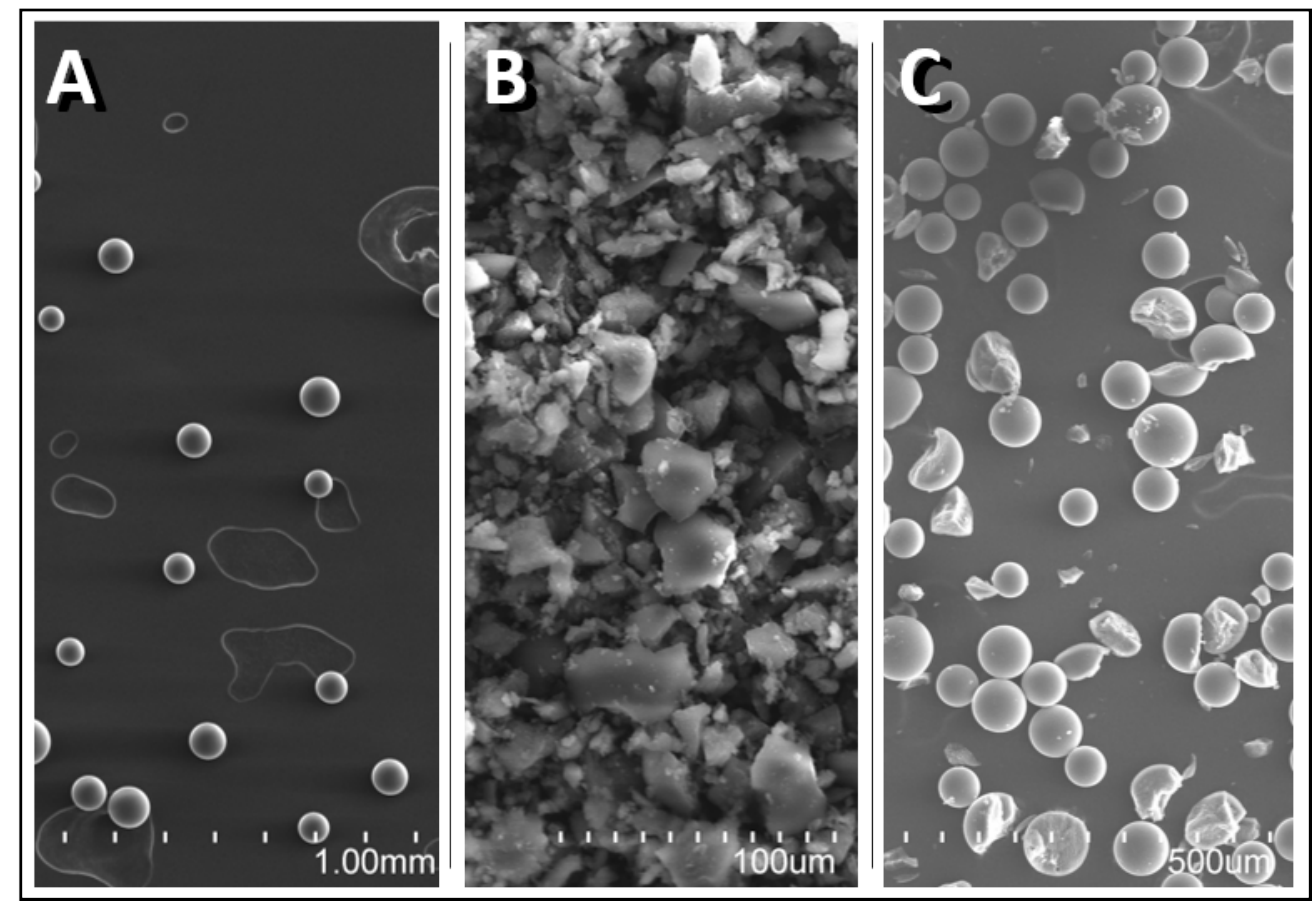

Figure 11. Comparison of SEM images of fresh TEVA resin (A) with fast stirring after $24 \mathrm{~h} \mathrm{(B)}$ and slower stirring after $48 \mathrm{~h}(\mathrm{C})$. 
The reduction in stirring speed significantly limited the breakage observed in the resin. However, to limit the possibility of resin breakage and subsequent frit clogging in the future on the prepFAST-MC2, it was decided to change column frits with each new batch of resin slurry and to stir the resin at a speed that creates minimum breakage while ensuring that the slurry remains mixed and relatively homogenous. Additionally, future resin breakage should be minimized in the new prepFAST-SR, as updated stir plates are controlled by the ESI software, which turns the stir bars off between sample runs.

\subsubsection{Characterization of System Process Blanks}

Process blanks are samples that have no intentionally added $\mathrm{U}$ or Pu but that contain all the reagents used and are taken through all steps of the analytical procedure. For the purposes of these studies, the process blank demonstrates the amount of U/Pu that is inherent to the "process" or the ESI system. It was expected that very little $\mathrm{Pu}$ would be present because of the lack of naturally occurring $\mathrm{Pu}$. However, $\mathrm{U}$ is ubiquitous throughout the environment and will generally be observed at some background level even in process blanks coming from cleanrooms. Uranium can be inherently present in materials (e.g., plastics, Teflon, glass) that contact the samples and in the reagents used, and there can even be a contribution from laboratory air. While steps are taken to reduce the amount of natural $U$ present (i.e., acid leaching of new containers, use of ultra-pure reagents), some $\mathrm{U}$ background remains. The amount of $\mathrm{U} / \mathrm{Pu}$ in the process blanks is typically measured by the addition of internal isotopic spike standards, commonly referred to as IDMS. With a well-characterized IDMS tracer, the amount of $U$ and Pu added to a blank sample by the system can be accurately determined. For these experiments (as well as for all other experiments described), the prep $F A S T$-MC2 was moved from the cleanroom into a standard chemical prep laboratory without any cleanroom infrastructure. All chemicals, reagents, samples, and spikes were still prepared in an ISO class 5 or 6 cleanroom and then brought to the prepFAST-MC2. Resin was prepared in the lab with the system.

The IDMS results for the automated process blanks and manual chemistry process blanks prepared in cleanroom laboratories over a 4 year period for $U$ are compared in Figure 12. The manual process blanks were generated in parallel with samples with various actinide concentrations and isotopic compositions and generated an average $\pm 2 \sigma$ process blank value of $0.057 \pm 0.088 \mathrm{ng}(\mathrm{n}=47)$ for $\mathrm{U}$. The automated system yielded $U$ process blanks with an average $\pm 2 \sigma$ value of $0.01503 \pm 0.00042 \mathrm{ng}(\mathrm{n}=26)$. While the values are not statistically different based on the expanded uncertainty of the manual separation method, the automated method did produce significantly more consistent blanks throughout the course of operation. Several factors may contribute to the lower blank levels observed, including less handling of the samples during separation, the completely closed sample lines, and smaller elution volumes used for this method. 


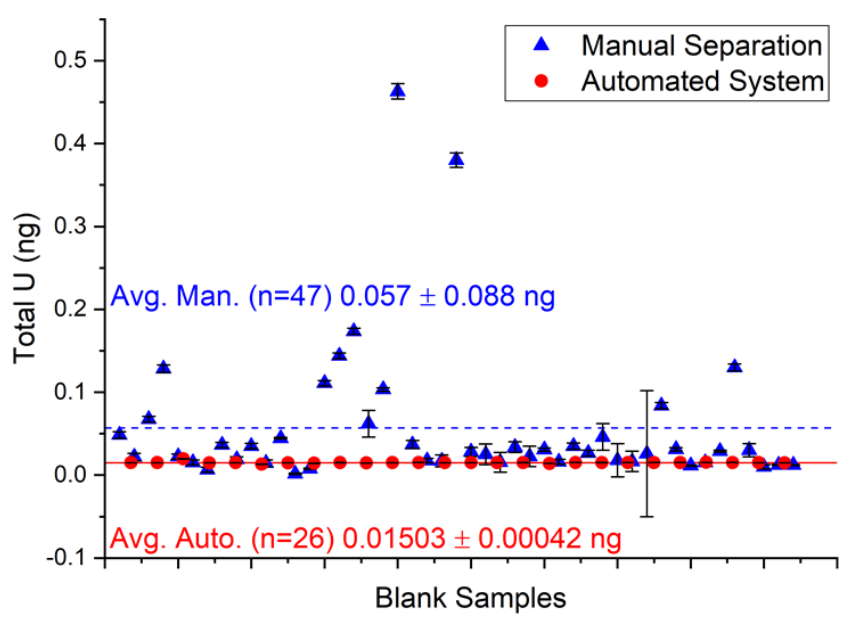

Figure 12. Total $U$ in automated (red circle) and manual (blue triangle) process blanks with $2 \sigma$ error bars and average lines as determined by IDMS.

The replicate analyses of the automated Pu process blanks yielded an average $\pm 2 \sigma$ of $0.0006 \pm 0.0025 \mathrm{pg}$ $(n=27)$. The comparison of the automated Pu process blanks and the manual process blanks over a 4 year period is shown in Figure 13. Like the U process blanks, the Pu process blanks show a higher level of reproducibility with smaller associated uncertainties. Similar factors, including less handling of the samples during separation, smaller elution volumes, and a closed system, may have contributed to the improved process blanks for $\mathrm{Pu}$ as well.

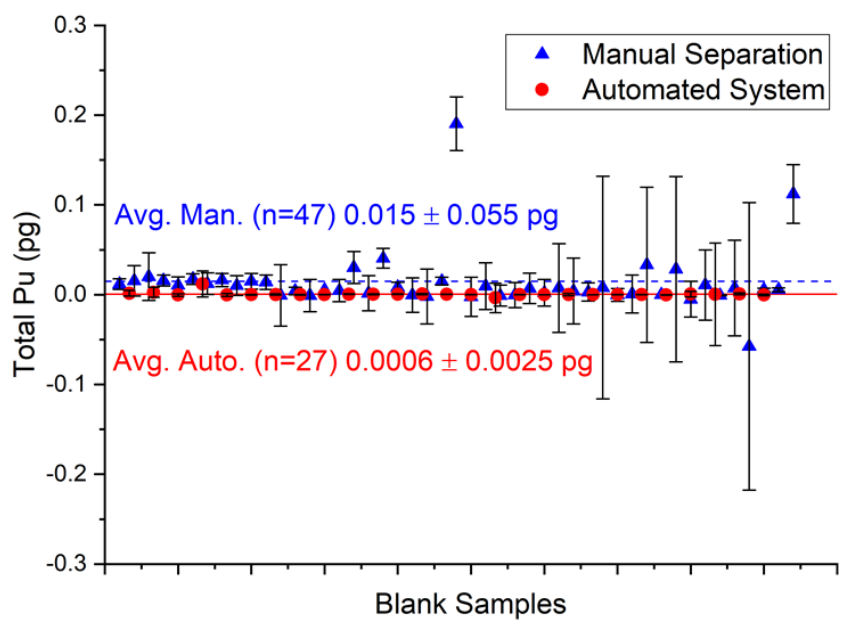

Figure 13. Total Pu in automated (red circle) and manual (blue triangle) process blanks with $2 \sigma$ error bars and average lines as determined by IDMS.

An initial concern with unattended overnight operation of the prepFAST-MC2 was the amount of time that elapsed between the addition of redox stabilizers $\left(\mathrm{FeSO}_{4}\right.$ and $\left.\mathrm{NaNO}_{2}\right)$ and the separation of the sample. Figure 14 and Figure 15 plot the measured counts of the ${ }^{233} \mathrm{U}$ and ${ }^{244} \mathrm{Pu}$ spikes, respectively, across the nine replicate blanks separated in 1 day. If a breakdown of the redox stabilizers was occurring during this time frame, the expected trend would be a decrease in counts of the spike, indicating a decrease in the percentage of recovery of the chemistry process. However, as Figure 14 and Figure 15 show, no clear decreasing trend in the measured counts over the course of a day was observed. This demonstrates that preparing all samples, with the redox reagents, together daily at the beginning of a separations sequence is adequate for unattended overnight operation. 


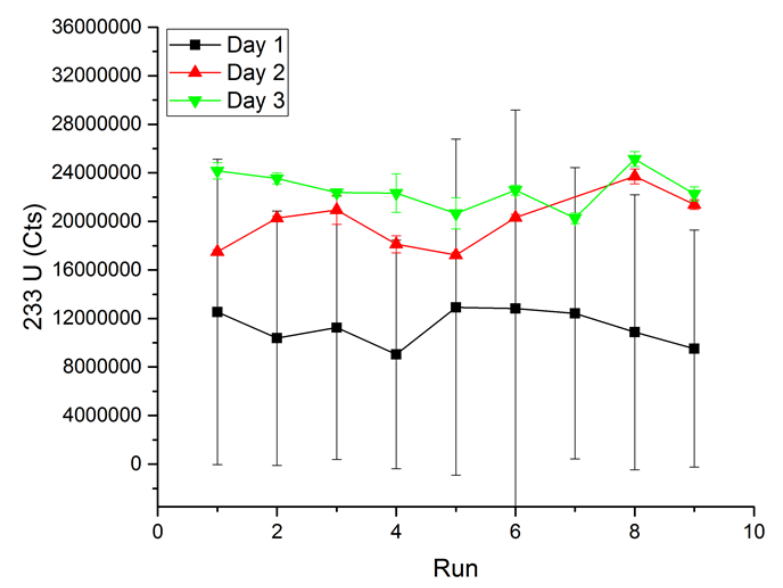

Figure 14. Counts of $U$ in blanks spiked with IRMM-57 $\left({ }^{233} U\right)$.

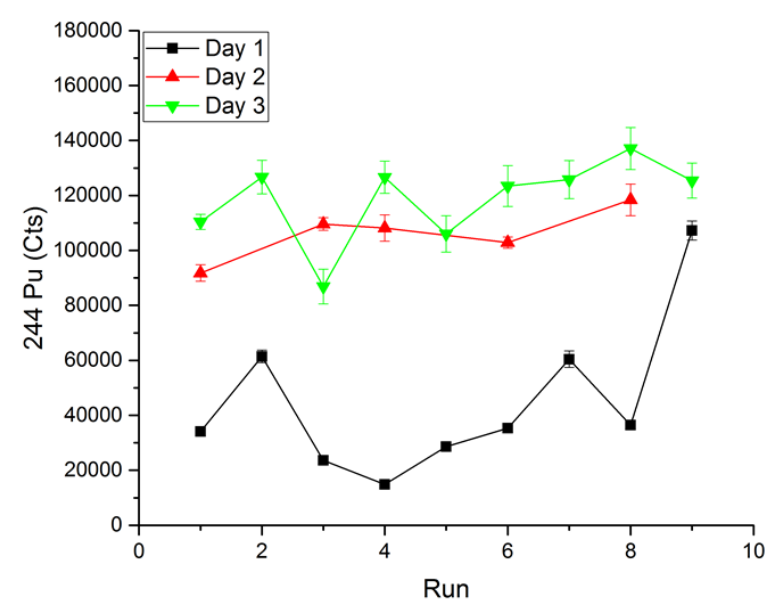

Figure 15. Counts of $\mathrm{Pu}$ in blanks spiked with RAL-22 $\left({ }^{244} \mathrm{Pu}\right)$.

As mentioned previously, the operation of the prepFAST-MC2 for these experiments occurred outside a cleanroom, whereas the samples and reagents were prepared in the cleanroom. To some degree, this represents a worst-case scenario for cleanliness. The fact that the system maintained blank levels on the order of the manual chemistry conducted in a cleanroom is encouraging for the potential use of this equipment in laboratories without access to expensive cleanroom infrastructure. The low blanks achieved without filtered air are attributed to both the entirely sealed sample path and the reduced reagent volumes required for the chemistry. The updated prepFAST-SR comes equipped with an ULPA filter atop the sample enclosure. It ensures that everything on the sample tray, including both the initial samples and the dispensed, purified aliquots, is only exposed to filtered air. The expectation is that the system can operate as a miniature, portable cleanroom, and the initial results from the analysis of the blank levels strongly support this conclusion.

\subsubsection{Analysis of Separated CRM}

To further investigate the separation of $\mathrm{U} / \mathrm{Pu}$ using the ESI prepFAST-MC2, samples containing both a $\mathrm{U}$ (IRMM 183) and a Pu (NBL 137) CRM were separated on the automated system. The automated separation sequence was configured to separate blanks between every sample to ensure proper washout between samples. The total initial amount of $\mathrm{U}$ or $\mathrm{Pu}$ present in a sample is described in Table 9 for each set of studies. 
Table 9. Approximate amounts of total U (IRMM-183) and Pu (NBL-137) CRMs in a sample for each set of experiments. ${ }^{9}$

\begin{tabular}{|l|l|l|}
\hline CRM separations & \multicolumn{1}{|c|}{$\begin{array}{c}\text { Total U } \\
(\mathbf{n g})\end{array}$} & $\begin{array}{c}\text { Total Pu } \\
(\mathbf{p g})\end{array}$ \\
\hline Initial separations & $25-30$ & $13-15$ \\
\hline Swipe matrix & $20-25$ & 6 \\
\hline High concentrations & $150-165$ & $145-151$ \\
\hline Low concentrations & 1.5 & 2.8 \\
\hline $\begin{array}{l}\text { Mid-level } \\
\text { concentrations }\end{array}$ & 50 & 4.5 \\
\hline Pu recovery & 4 & 0.05 \\
\hline Metal interferences & 45 & 2.5 \\
\hline
\end{tabular}

Initial separations included 10 replicate samples and 13 blanks that were collected over a 4 day period by different operators each day. All major and minor isotope ratios were measured by MC-ICP-MS in conjunction with mass bias calibration standards, several additional acid blanks, and CRM IRMM 183 or NBL 137 control standards that had not been processed through the prepFAST-MC2. The results from the samples separated on the automated system are displayed in Table 10 . The major ${ }^{235} \mathrm{U} /{ }^{238} \mathrm{U}$ ratio was accurate to within $0.1 \%$ of the certified value, and the ${ }^{236} \mathrm{U} /{ }^{238} \mathrm{U}$ ratio was accurate to within $0.3 \%$ of the certified value. The low signal intensity on the Faraday cups limited the measurement of ${ }^{234} \mathrm{U}$ during initial separations. The Pu samples were within $0.1 \%$ of the certified values for the ${ }^{240} \mathrm{Pu} /{ }^{239} \mathrm{Pu}$ and ${ }^{242} \mathrm{Pu} /{ }^{239} \mathrm{Pu}$ ratios. The ${ }^{241} \mathrm{Pu} /{ }^{239} \mathrm{Pu}$ ratio had very low count rates but was within $2.5 \%$ of the certified value.

Table 10. Major and minor isotope ratios for $U$ and $P u$ compared with $C R M$ values during "initial separations" on the prepFAST-MC2.

\begin{tabular}{|c|c|c|c|}
\hline Ratio & Measured value $(2 \sigma)$ & Certified value $(2 \sigma)$ & Measured/certified $(2 \sigma)$ \\
\hline${ }^{235} U /{ }^{238} U$ & $0.0032196(27)$ & $0.0032157(16)$ & $1.0012(20)$ \\
\hline${ }^{236} \mathrm{U} /{ }^{238} \mathrm{U}$ & $0.0001426(22)$ & $0.000148358(54)$ & $0.961(30)$ \\
\hline${ }^{240} \mathrm{Pu} /{ }^{239} \mathrm{Pu}$ & $0.24097(73)$ & $0.24077(37)$ & $1.0008(68)$ \\
\hline${ }^{241} \mathrm{Pu} /{ }^{239} \mathrm{Pu}$ & $0.006627(59)$ & $0.006793(78)$ & $0.975(29)$ \\
\hline${ }^{242} \mathrm{Pu} /{ }^{239} \mathrm{Pu}$ & $0.01560(13)$ & $0.015611(52)$ & $1.000(18)$ \\
\hline
\end{tabular}

The analysis of CRM samples derived from loaded swipe samples (Table 9, swipe matrix) demonstrated no matrix effect on the separation of $\mathrm{U}$ and $\mathrm{Pu}$. While the isotope ratios for $\mathrm{Pu}$ were unperturbed, the $\mathrm{U}$ isotope ratios demonstrated some variation due to the amount of natural $U(2.54 \pm 0.04 \mathrm{ng})$ inherent to the cotton swipe. Therefore, the measured ratios were corrected by subtracting the average amount of natural $\mathrm{U}$ in the swipe blank from the sample results; after correction, the measured ratios were in good agreement with the certified ratios, with some variation due to the variability observed in the amount of natural $\mathrm{U}$ in the swipes.

The operating range of the prepFAST-MC2 was examined with varying concentrations of $\mathrm{U}$ and $\mathrm{Pu}$ (Table 9, high, mid, and low concentrations) up to $\sim 165 \mathrm{ng} \mathrm{U}$ and $\sim 151 \mathrm{pg} \mathrm{Pu}$. Maximum sample amounts were determined by radioactivity limits based on benchtop use with additional safety controls. The results, even at the highest levels of $\mathrm{U}$ or $\mathrm{Pu}$, demonstrated $99.8 \%$ removal of the $\mathrm{U}$ from the purified $\mathrm{Pu}$ fraction and $99.9 \%$ removal of $\mathrm{Pu}$ from the purified $\mathrm{U}$ fraction, both of which are important for MC-ICPMS measurements. Carryover of $U$ in the blank immediately following three replicate high-concentration samples was not observed. Sample carryover of $\sim 20 \mathrm{fg}$ of Pu was observed in the blank immediately 
following triplicate high-Pu-concentration (151 pg, NBL 137) samples. However, results from additional blanks showed no detectable $\mathrm{Pu}$, indicating that processing a single blank through the system is enough to return it to the baseline. Additionally, a system cleaning method was developed to leach the internal components of the system so that cleanliness can be ensured after future high-level samples.

The recovery of $U$ from UTEVA resin is well characterized as being near quantitative, as was observed with the automated system during initial studies. However, Pu recovery may be less consistent, especially at ultra-trace levels. Therefore, the recovery of $50 \mathrm{fg}$ of NBL 137 from the automated system was examined with samples containing $3 \mathrm{ng}$ of U. After separation, IDMS was used to determine the amount of $\mathrm{Pu}$ in the sample and found that recovery was $>80 \%$. Even at these low levels of $\mathrm{Pu}$, the measured ${ }^{240} \mathrm{Pu} /{ }^{239} \mathrm{Pu}$ ratio was in good agreement with the certified ratio.

The measured-over-certified $(\mathrm{M} / \mathrm{C})$ values for the $\mathrm{U}$ isotope ratios are displayed in Figure 16 . The $\mathrm{U}$ data has been corrected for instrument bias determined from 3 year average control charts. A small number of samples demonstrate a significant $(>3 \sigma)$ difference between the measured and certified ratio. For the swipe samples, this was primarily attributed to the deviation in the amount of natural $U$ present in the swipe. For other samples, the variability was attributed to potential poor recovery after sample concentration and preparation of ICP-MS analysis. Plutonium isotope data is shown in Figure 17 and is calculated relative to decay-corrected $\mathrm{M} / \mathrm{C}$ values for NBL 137. The minor Pu ratios for lowconcentration samples displayed larger expanded uncertainties as a result of the small signal associated with the isotopes. Individual data points for both $\mathrm{U}$ and $\mathrm{Pu}$ are plotted; the error bars represent the expanded uncertainty $(2 \sigma)$ of the isotope ratio measurement. 


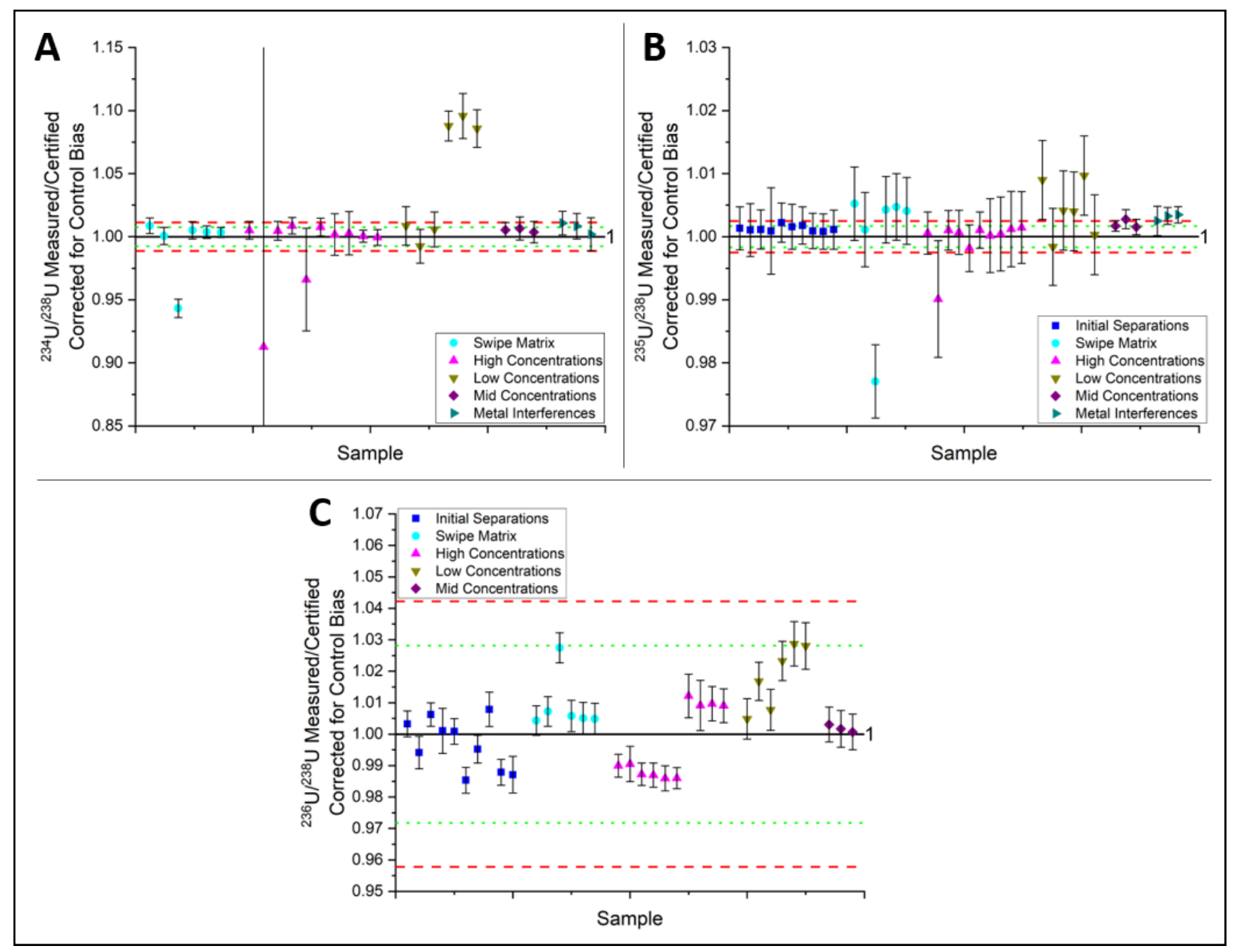

Figure 16. $\mathrm{U}$ M/C isotope ratios compared with instrument controls with $2 \sigma$ (green, dotted line) and $3 \sigma$ (red, dashed line) error lines for IRMM 183 instrument controls. ${ }^{9}$ 


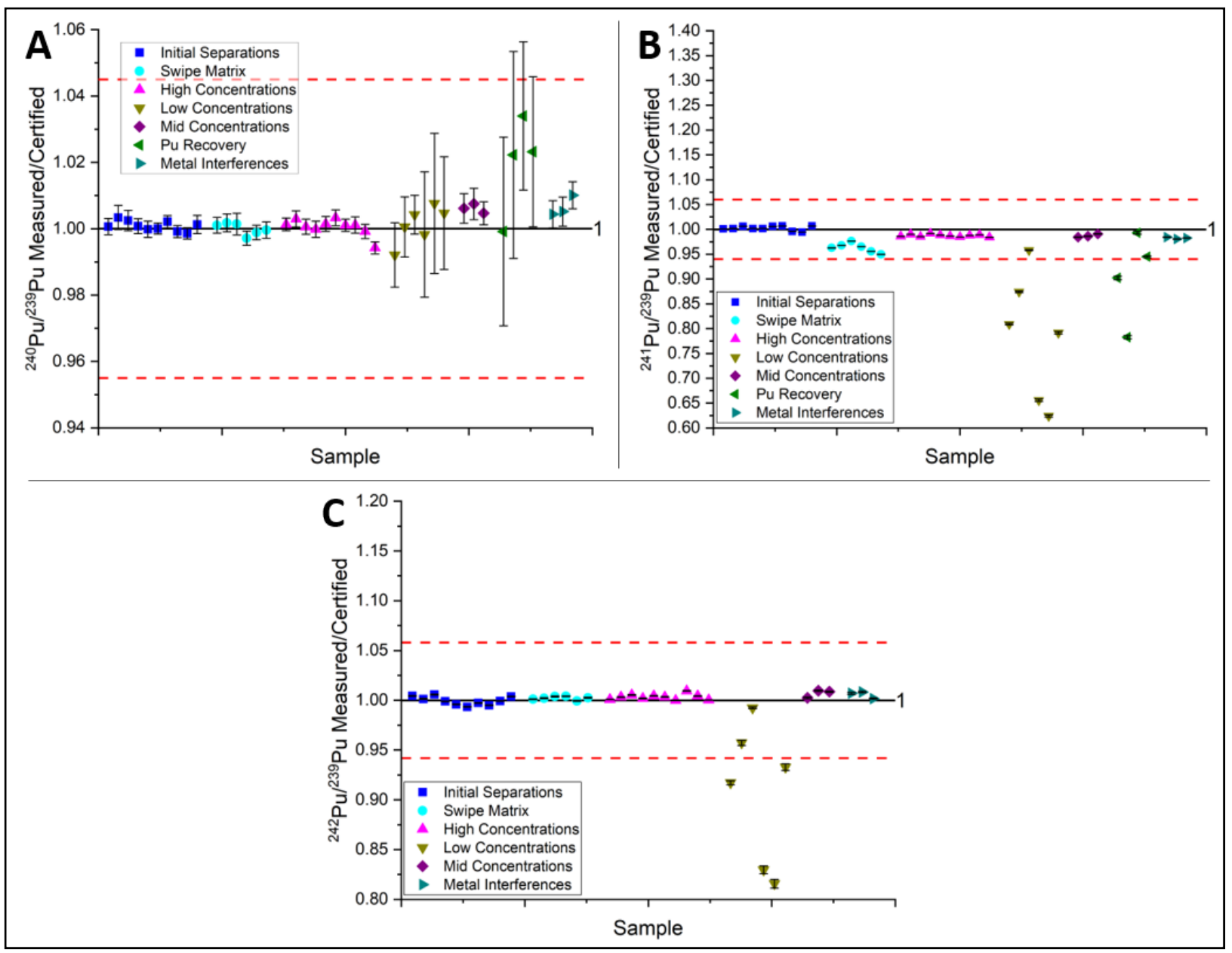

Figure 17. Pu M/C isotope ratios for NBL 137 with $2 \sigma$ error lines (red, dashed line) for NBL 137 controls. ${ }^{9}$

Examination of blanks processed in conjunction with CRM samples showed good agreement with IDMS process blanks for both $\mathrm{U}(\sim 0.022 \mathrm{ng})$ and $\mathrm{Pu}(\sim 0.0005 \mathrm{pg})$. Additionally, the major $\mathrm{U}$ ratio was monitored for cross-contamination over the course of these studies, and the U blanks exhibited a natural ${ }^{235} \mathrm{U} / 238 \mathrm{U}$ isotope ratio throughout.

\subsubsection{Metal Interferences}

Significant amounts of heavy metals such $\mathrm{W}, \mathrm{Pt}, \mathrm{Pb}$, and $\mathrm{Th}$ are known to create interferences in an ICPMS plasma that can affect the measurement of $U$ and $\mathrm{Pu}$. Additionally, significant quantities of any metals may occupy binding sites in the resin columns and impact the successful purification of $\mathrm{U}$ and $\mathrm{Pu}$ aliquots. To test for these issues, elements either expected to be present in swipe samples in high abundance $(\mathrm{Pb}, \mathrm{Th})$ or elements, however rare, that are known to cause interferences in the ICP-MS (Pt, $\mathrm{Au}, \mathrm{Bi})$ were spiked into samples and separated on the original prepFAST-MC2. Initial separations were verified with blanks spiked with the metals. The samples showed near-quantitative removal of all elements in the distinct fractions.

After initial verification with blanks, the same contaminants were spiked into samples containing $U$ and $\mathrm{Pu}$ CRMs. A fraction of each purified aliquot was measured by HR-ICP-MS to quantify the removal of the contaminants, and the remainder was submitted for MC-ICP-MS analysis to ensure no negative impact on the actinide isotope ratio determinations. The list of contaminants examined and their starting and final concentrations in the CRM spiked samples are shown in Table 11. The results confirm that the 
system accomplished removal of all species, even at significant quantities, for both the U- and Pucontaining fractions. Furthermore, no significant deviations were observed in the major or minor $\mathrm{U}$ or $\mathrm{Pu}$ isotopic ratios (Figure 16 and Figure 17).

Table 11. Percentage reduction of contaminant elements in $U$ and Pu fraction by the prepFAST-MC2.

\begin{tabular}{cccccc}
\hline & \multicolumn{2}{c}{ U fraction } & \multicolumn{2}{c}{ Pu fraction } \\
\cline { 2 - 6 } Element & $\begin{array}{c}\text { Starting } \\
\text { concentration } \\
(\mathbf{n g} / \mathbf{m L})\end{array}$ & $\begin{array}{c}\text { Final } \\
\text { concentration } \\
(\mathbf{n g} / \mathbf{m L})\end{array}$ & $\begin{array}{c}\text { Percent } \\
\text { reduction } \\
\mathbf{( \% )}\end{array}$ & $\begin{array}{c}\text { Final } \\
\text { concentration } \\
(\mathbf{n g} / \mathbf{m L})\end{array}$ & $\begin{array}{c}\text { Percent } \\
\text { reduction } \\
(\%)\end{array}$ \\
\hline $\mathbf{Z r}$ & 1000 & 17.0 & 98 & 0.4 & 100 \\
$\mathbf{M o}$ & 1000 & 0.2 & 100 & 0.4 & 100 \\
$\mathbf{R u}$ & 10 & 0.1 & 99 & 0.1 & 100 \\
$\mathbf{W}$ & 1000 & 0.2 & 100 & 0.2 & 100 \\
$\mathbf{O s}$ & 10 & -0.3 & 103 & -0.1 & 101 \\
$\mathbf{P t}$ & 10 & 0.1 & 100 & 0.1 & 99 \\
$\mathbf{A u}$ & 10 & 0.2 & 98 & 0.1 & 100 \\
$\mathbf{H g}$ & 10 & 0.2 & 100 & 0.2 & 100 \\
$\mathbf{T l}$ & 10 & -0.2 & 101 & 0.0 & 100 \\
\hline $\mathbf{P b}$ & 10000 & 0.8 & 100 & 0.6 & 100 \\
\hline $\mathbf{B i}$ & 1000 & 0.2 & 100 & 0.1 & 100 \\
$\mathbf{T h}$ & 5000 & 5.1 & 100 & 0.6 & 100 \\
\hline
\end{tabular}

\subsubsection{Archived Swipe Samples}

The final method of validation using archived samples (with explicit IAEA approval for this activity) was conducted using samples from 2014-2016. The samples were analyzed for U and Pu isotopic ratios only, as sample concentrations may change over time because of evaporation or loss to vial walls. Typically, after processing, only $10-20 \%$ of the original sample is saved for archiving. Four samples were chosen from archived IAEA samples to test a variety of isotopic and concentration ranges for $\mathrm{U}$ and $\mathrm{Pu}$. In the original total samples, Sample 1 had $\sim 30 \mathrm{ng}$ of low-enriched U and $\sim 3 \mathrm{pg}$ of Pu; Sample 2 had $\sim 8 \mathrm{ng}$ of natural $\mathrm{U}$ and $\sim 10 \mathrm{pg}$ of $\mathrm{Pu}$; Sample $3 \mathrm{had} 10 \mathrm{ng}$ of low-enriched $\mathrm{U}$ and $<2.5 \mathrm{fg}$ of Pu; Sample 4 had $\sim 3 \mu \mathrm{g}$ of depleted $\mathrm{U}$ and $\sim 50 \mathrm{pg}$ of Pu. Samples 1-3 archived only $\sim 15 \%$ of the original sample, whereas the $\mathrm{U}$ and $\mathrm{Pu}$ content in Sample 4 allowed $\sim 85 \%$ of the sample to be archived. The minor Pu isotope ratios previously reported were not larger than their $2 \sigma$ value and were not a point of focus for these studies.

Table 12 shows a comparison of the measured vs. reported isotope ratios of the separated $\mathrm{U}$ and $\mathrm{Pu}$ fractions from the four archived samples. Sample 1, from 2014, experienced some degree of evaporation after being removed from archive storage. Therefore, $3 \mathrm{M} \mathrm{HNO}_{3}$ was added to bring the volume up to $\sim 1.5 \mathrm{~mL}$ before separation. MC-ICP-MS results for U isotopics showed very good agreement with the previously reported values (Table 12). However, because of the affinity of Pu for PFA vials - which is well known to impact the concentration of Pu solutions over time - and the age of the archived aliquot, the signal of ${ }^{240} \mathrm{Pu}$ was insufficient for accurate measurement. To ensure all $\mathrm{Pu}$ was in solution in the remaining samples, HF was added to give a final concentration of $\sim 50 \mathrm{mM}$. The samples were heated overnight to help leach the Pu from the PFA vial and then dried down to remove the HF from the sample. The samples were then resuspended in $3 \mathrm{M} \mathrm{HNO}_{3}$ before separation. The major $\mathrm{U}$ and $\mathrm{Pu}$ isotopic ratios for Sample 2 were consistent with previously reported values. Although the ${ }^{234} \mathrm{U} /{ }^{238} \mathrm{U}$ isotopic ratio matched the reported value, the ${ }^{236} \mathrm{U} / 238 \mathrm{U}$ isotope ratio was limited by the count rate. Sample 3 had a very 
low count rate for $\mathrm{Pu}$, but the measured ${ }^{235} \mathrm{U} / 238 \mathrm{U}$ and ${ }^{236} \mathrm{U} / 238 \mathrm{U}$ isotope ratios were within $2 \sigma$ of the reported values, and the measured ${ }^{236} \mathrm{U} / 238 \mathrm{U}$ ratio was within $3 \sigma$. The high $\mathrm{U}$ and Pu content in Sample 4 allowed for the separations and analyses to be carried out in triplicate on different days. The measured results for all isotope ratio measurements demonstrated excellent agreement with the reported values and showed no significant difference from the reported values. Moreover, all measured values were well within IAEA NWAL data quality limits.

Table 12. Comparison of measured vs. reported values for major and minor $\mathrm{U}$ isotopic ratios and major $\mathrm{Pu}$ isotopic ratios with $1 \sigma$ errors (N.D. is nondetectable) for archived ORNL environmental samples. ${ }^{9}$

\begin{tabular}{|c|c|c|c|c|c|c|c|c|}
\hline Measured/reported & ${ }^{234} \mathbf{U}{ }^{238} \mathbf{U}$ & $\mathbf{1 \sigma}$ & ${ }^{235} \mathbf{U} /{ }^{238} \mathbf{U}$ & $\mathbf{1 \sigma}$ & ${ }^{\mathbf{2 3 6}} \mathbf{U} /{ }^{\mathbf{2 3 8}} \mathbf{U}$ & $\mathbf{1 \sigma}$ & ${ }^{240} \mathbf{P u} /{ }^{\mathbf{2 3} 9} \mathbf{P u}$ & $\mathbf{1 \sigma}$ \\
\hline Sample 1 & $99.88 \%$ & $0.70 \%$ & $99.92 \%$ & $0.95 \%$ & $99.40 \%$ & $0.64 \%$ & N.D. & N.D. \\
\hline Sample 2 & $99.48 \%$ & $1.54 \%$ & $99.80 \%$ & $0.65 \%$ & N.D. & N.D. & $100.7 \%$ & $2.3 \%$ \\
\hline Sample 3 & $97.04 \%$ & $1.09 \%$ & $98.35 \%$ & $0.81 \%$ & $96.28 \%$ & $1.52 \%$ & N.D. & N.D. \\
\hline Sample 4 - 1 & $100.12 \%$ & $0.69 \%$ & $99.95 \%$ & $0.79 \%$ & $99.42 \%$ & $0.94 \%$ & $100.5 \%$ & $2.9 \%$ \\
\hline Sample 4-2 & $99.87 \%$ & $0.57 \%$ & $100.11 \%$ & $0.79 \%$ & $99.65 \%$ & $0.89 \%$ & $100.9 \%$ & $3.6 \%$ \\
\hline Sample 4-3 & $99.95 \%$ & $0.70 \%$ & $100.10 \%$ & $0.79 \%$ & $99.53 \%$ & $0.95 \%$ & $100.2 \%$ & $4.7 \%$ \\
\hline
\end{tabular}

\subsection{COMPARISON WITH CURRENT NWAL CAPABILITY}

The chemistry of the ESI prepFAST-MC2 was designed to be as close to the ORNL NWAL manual chemistry as possible, with differences outlined in Table 5. The use of smaller columns allows for smaller elution volumes, which can in turn reduce the amount of time spent drying down a sample before MCICP-MS analysis. Additionally, the smaller elution volumes may lead to lower U and Pu content in process blanks. One notable change that has been made is in the elution of the Pu from the TEVA column. Current ORNL NWAL manual chemistry methods use $\mathrm{NH}_{4} \mathrm{I}$ as a reducing agent to help remove $\mathrm{Pu}$ from the TEVA column through the reduction of $\mathrm{Pu}^{+4}$ to $\mathrm{Pu}^{+3}$. However, initial studies revealed high $\mathrm{Pu}$ recoveries without the addition of $\mathrm{NH}_{4} \mathrm{I}$, and Eichrom suggests low acid concentrations can also remove $\mathrm{Pu}$ from TEVA resin without the reduction step. ${ }^{9-11}$ Additionally, $\mathrm{NH}_{4} \mathrm{I}$ is photosensitive, and the prototype prepFAST-MC2 has two LED lights behind the columns and in the lower cabinet that are on continuously. The relatively quick decomposition of $\mathrm{NH}_{4} \mathrm{I}$ in aqueous solution and sensitivity to light would necessitate that the solution be made fresh daily. Examination of Pu recovery on the prepFASTMC2 demonstrated $>80 \%$ recovery at $50 \mathrm{fg}$ of Pu without a reducing agent.

\subsection{MICROWAVE DIGESTION OF SWIPE BLANKS}

Based on tests conducted by CEM, the manufacturer of the microwave system in use at the analytical lab at ORNL, microwave digestion of swipes alone is not a suitable replacement for furnace ashing of cotton swipes. The amount of organic material present in the swipe itself presents a significant challenge for this digestion method. The full CEM report is presented in Appendix A. However, ORNL conducted a further study looking at a hybrid ashing method consisting of a single furnace ashing step, followed by microwave digestion of the ash residue. If suitable, this could be a faster method and one more suitable to automation, compared with the multiple (two or more) dry ashing steps that are often required to achieve full digestion of a swipe.

Using the hybrid method (one furnace ashing step followed by the microwave digestion method outlined in Table 7), it was possible to fully digest the blank swipe material. After the swipe was digested in the microwave and the solution was cooled to room temperature, the residue was transferred to a PFA vial and IRMM 183 ( $\sim 80 \mathrm{ng})$ was added to the sample. The resulting sample was then dried down and 
resuspended in $3 \mathrm{M} \mathrm{HNO}_{3}$ before being separated on a $2 \mathrm{~mL}$ UTEVA cartridge following the ORNL manual NWAL chemistry method. The MC-ICP-MS results showed good agreement with the certified isotopic values. Although this hybrid digestion option is viewed as promising, it would need to be more fully investigated in a separate research effort.

\subsection{MATRIX REDUCTION USING EVAPOCLEAN SYSTEM}

\subsubsection{Reducing Background Counts through Leaching}

The conventional ORNL cleanroom method of leaching calls for separate solutions of reagent-grade $6 \mathrm{M}$ $\mathrm{HCl}, 8 \mathrm{M} \mathrm{HNO}_{3}$, and Type 1 water, each at a volume of approximately $2 \mathrm{~L}$. New vials are rinsed with deionized water, placed in $6 \mathrm{M} \mathrm{HCl}$ at $50{ }^{\circ} \mathrm{C}$ for $16 \mathrm{~h}$, and rinsed. The process is followed in the same manner with $8 \mathrm{M} \mathrm{HNO}_{3}$ and then finally water. It takes a total of 3 days and 3 to $4 \mathrm{~h}$ of labor for approximately 25 vials. Although the EvapoClean system would take roughly an equivalent number of labor hours, the system would require only $\sim 8 \mathrm{~h}$ to clean the same number of vials. A big advantage of the EvapoClean is the reduced acid volume requirement. Each position (six lids, six vials) uses $5 \mathrm{~mL}$ of $8 \mathrm{M}$ $\mathrm{HNO}_{3}$, totaling $60 \mathrm{~mL}$ of acid. The acid is heated, channeling ultra-pure vapors into the top container, which then condenses and flows downward (Figure 6). It is not necessary to renew the acid often because the contaminants remain at the bottom of the refluxing vial while the rising vapor remains clean.

A comparison of counts of ${ }^{235} \mathrm{U}$ and ${ }^{238} \mathrm{U}$ from new unleached PFA vials, new leached PFA vials, and new PFA vials leached through the EvapoClean system is shown in Figure 18. Conventional leaching methods and the EvapoClean leaching method both reduced the counts by an order of magnitude compared with the unleached PFA vials. EvapoClean leaching methods further reduced the counts of $U$ by half compared with conventional ORNL leaching methods.

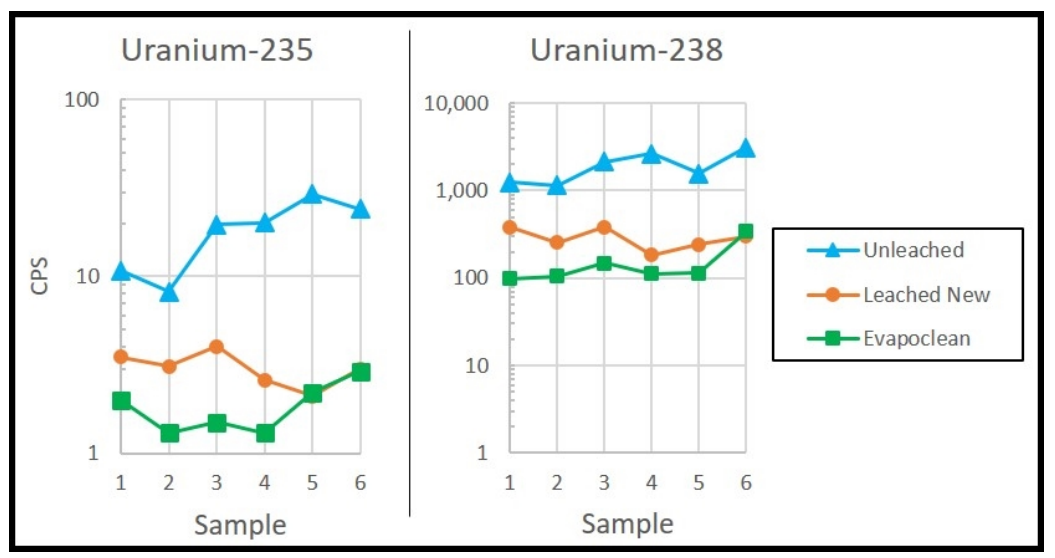

Figure 18. Comparison of background counts in three sets of PFA vials for selected isotopes.

Of further interest was the efficacy of leaching vials after they had been used for sample containment. To test the efficacy, vials that had previously held $\sim 1 \mathrm{ng}$ of ${ }^{233} \mathrm{U}$ were submitted to both methods of leaching. There was not a noticeable difference in the counts of ${ }^{233} \mathrm{U}$ and ${ }^{235} \mathrm{U}$ between the leaching methods, as shown in Figure 19. However, ${ }^{238} \mathrm{U}$ counts were five times lower on average with the EvapoClean method than with the conventional method. This is likely because the EvapoClean method distills the acid used for cleaning as part of the process itself, whereas acid in the traditional leaching method will become slightly contaminated over time. Vials that were previously used for NBL 137 (2 pg) were also cleaned through the EvapoClean system, and counts were reduced to sub-femtogram levels (data not shown). 


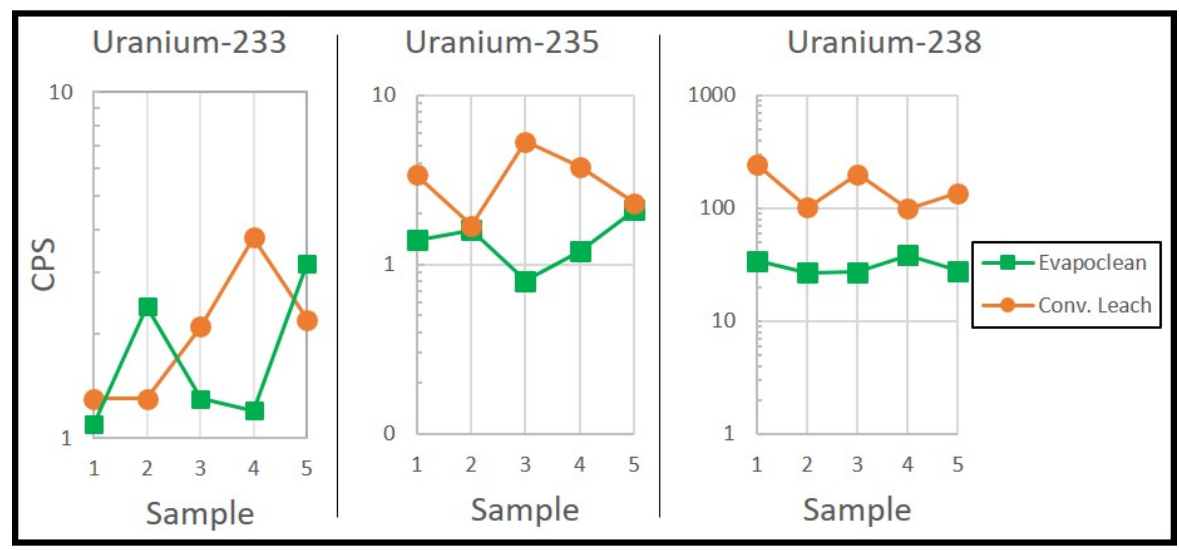

Figure 19. Counts of selected isotopes from previously used PFA vials after conventional leaching and EvapoClean leaching method.

\subsubsection{Decreasing Cross-Contamination via Sample Concentration in a Closed Environment}

Matrix reduction and conversion is one of the most time-consuming steps in the sample preparation process. Current methods can expose samples to cross-contamination from other samples processed concurrently through traditional ORNL acid dry-down methods. The individual enclosures for each sample used by the EvapoClean, illustrated in Figure 6, protect them from cross-contamination. Initial studies to determine recovery were carried out using a mixture of metals at $0.5 \mathrm{ppb}$ (not including $\mathrm{U}$ or $\mathrm{Pu}$ ) in dilute $\mathrm{HNO}_{3}$. The results of this study are outlined in Table 13. Briefly, of the 40 metals, only 3 metals ( $\mathrm{Au}, \mathrm{Pd}$, and Ta) demonstrated recoveries below 85\%; 3 additional metals ( $\mathrm{Pt}, \mathrm{W}$, and $\mathrm{Sn}$ ) were below $90 \%$ recovery. The remaining 34 elements showed recoveries greater than $90 \%$ at $130{ }^{\circ} \mathrm{C}$.

Table 13. Percentage recovery of selected metals that were evaporated at $130{ }^{\circ} \mathrm{C}$ from a metal concentration of $0.5 \mathrm{ppb}$ in $2 \% \mathrm{HNO}_{3}$.

\begin{tabular}{cc|cc|cc}
\hline Element & Percent recovery & Element & Percent recovery & Element & Percent recovery \\
\hline $\mathrm{Al}$ & $102 \pm 19$ & $\mathrm{Mg}$ & $92 \pm 12$ & $\mathrm{Ta}$ & $73 \pm 2$ \\
$\mathrm{Sb}$ & $91 \pm 3$ & $\mathrm{Mn}$ & $93 \pm 3$ & $\mathrm{Tl}$ & $93 \pm 3$ \\
$\mathrm{As}$ & $98 \pm 4$ & $\mathrm{Mo}$ & $96 \pm 3$ & $\mathrm{Sn}$ & $89 \pm 5$ \\
$\mathrm{Ba}$ & $92 \pm 3$ & $\mathrm{Ni}$ & $95 \pm 3$ & $\mathrm{Ti}$ & $93 \pm 4$ \\
$\mathrm{Be}$ & $108 \pm 13$ & $\mathrm{Nb}$ & $105 \pm 2$ & $\mathrm{~W}$ & $89 \pm 3$ \\
$\mathrm{Bi}$ & $96 \pm 7$ & $\mathrm{Pd}$ & $68 \pm 16$ & $\mathrm{~V}$ & $93 \pm 1$ \\
$\mathrm{~B}$ & $154 \pm 42$ & $\mathrm{P}$ & $104 \pm 25$ & $\mathrm{Zn}$ & $108 \pm 20$ \\
$\mathrm{Cd}$ & $90 \pm 1.5$ & $\mathrm{Pt}$ & $85 \pm 14$ & $\mathrm{Zr}$ & $100 \pm 6$ \\
$\mathrm{Ca}$ & $100 \pm 47$ & $\mathrm{~K}$ & $100 \pm 65$ & $\mathrm{In}$ & $91 \pm 6$ \\
$\mathrm{Cr}$ & $97 \pm 7$ & $\mathrm{Ag}$ & $93 \pm 3$ & $\mathrm{Fe}$ & $105 \pm 42$ \\
$\mathrm{Co}$ & $95 \pm 2$ & $\mathrm{Na}$ & $93 \pm 15$ & $\mathrm{La}$ & $97 \pm 4$ \\
$\mathrm{Cu}$ & $145 \pm 12$ & $\mathrm{Sr}$ & $92 \pm 3$ & $\mathrm{~Pb}$ & $90 \pm 5$ \\
$\mathrm{Ga}$ & $95 \pm 2$ & $\mathrm{Au}$ & $46 \pm 15$ & $\mathrm{Li}$ & $100 \pm 7$ \\
$\mathrm{Ge}$ & $93 \pm 4$ & - & - & - & - \\
\hline
\end{tabular}

Uranium recovery was examined using a solution matrix similar to the standard NWAL digestion matrix (10 mL, 3.6 $\mathrm{M} \mathrm{HNO}_{3}-2.5 \mathrm{M} \mathrm{HF}$ ) and IRMM 183 (5 ng). To determine the optimum operating 
temperature, $\mathrm{U}$ recovery was examined over the temperature range of 110 to $150{ }^{\circ} \mathrm{C}\left(\Delta=10^{\circ} \mathrm{C}\right)$. No significant change was observed in the percentage of recovery at different temperatures, shown in Figure 20. However, as expected, there was a correlation between the temperature and the amount of time required for complete matrix reduction. The lower the temperature, the longer the amount of time needed: $\sim 7 \mathrm{~h}$ for $110^{\circ} \mathrm{C}$ and $\sim 2.5 \mathrm{~h}$ for $150{ }^{\circ} \mathrm{C}$. MC-ICP-MS results showed no significant difference in the major or minor isotopic ratios for $\mathrm{U}$ after reconstitution in $2 \% \mathrm{HNO}_{3}$. Complete sample recovery required supervision near the end of the dry-down cycle, or moderate heating. The time required for moderate temperatures $\left(120\right.$ to $\left.130{ }^{\circ} \mathrm{C}\right)$ provided a significant improvement in the amount of time needed for matrix reduction compared with the previously used technique.

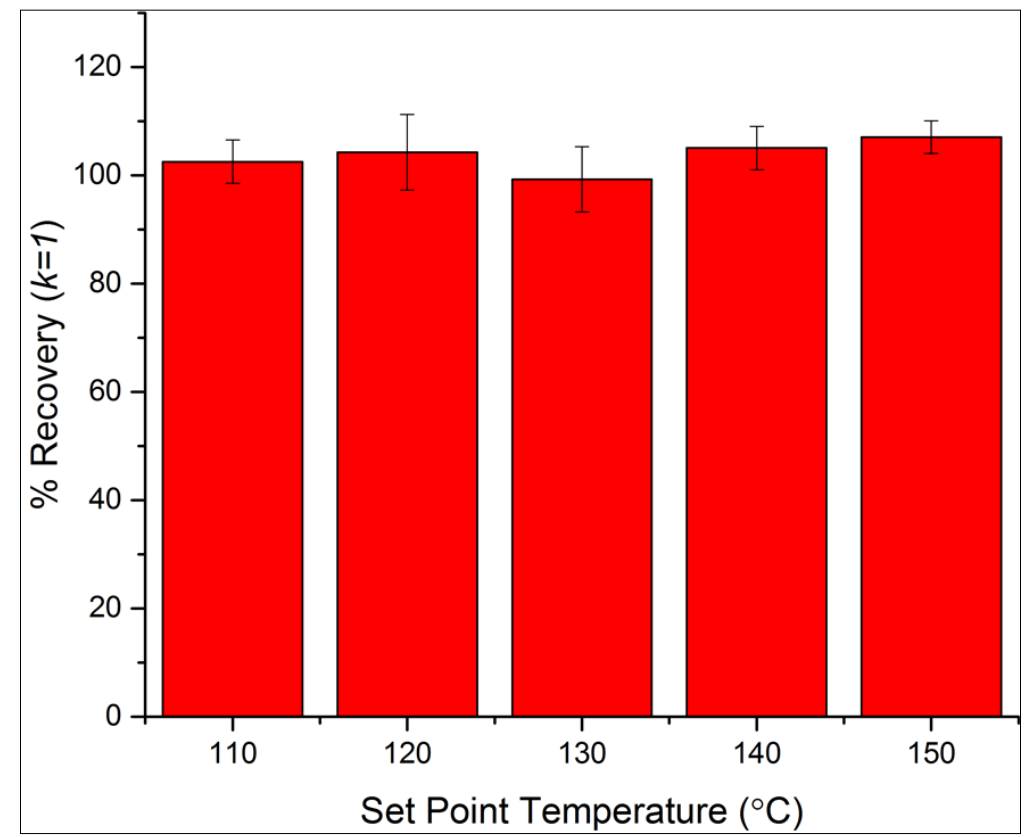

Figure 20. Percentage recovery of $U$ from matrix reduction using the EvapoClean system at various temperatures.

Plutonium recovery was examined at 120 and $130{ }^{\circ} \mathrm{C}$ and compared with standard dry-down box techniques using NBL $137(2-4 \mathrm{pg})$ with a ${ }^{244} \mathrm{Pu}$ tracer added to quantify the recovery in $2 \mathrm{~mL}$ of $3 \mathrm{M}$ $\mathrm{HNO}_{3}$. Samples dried down using the standard ORNL method yielded an average recovery of $72 \pm 39 \%$ $(\mathrm{n}=3)$. The EvapoClean system yielded higher recoveries at $89.0 \pm 6.3 \%(\mathrm{n}=4)$. Distillate from the EvapoClean system showed $<0.5 \mathrm{fg}$ of $\mathrm{Pu}$ and could be used to quantify loss if needed, whereas in the dry-down boxes, any loss of sample would remain unaccounted for. The EvapoClean system would ensure that if sample were lost to the distillate, it could be transferred back to the sample vial and dried down again without significant loss or contamination from an external source. Additionally, the dry-down boxes took twice as long $(\sim 3 \mathrm{~h})$ to completely dry the samples as did the EvapoClean method (90 min).

\section{NEWLY DESIGNED PREPFAST-SR SYSTEMS}

\subsection{SYSTEM CALIBRATION AND CRM SEPARATIONS}

Preliminary column calibration methods demonstrated good separation of $\mathrm{U}$ and $\mathrm{Pu}$ CRMs from a mixed sample. Elution profiles were similar to those generated on the original prototype (prepFAST-MC2) 
system. After verification of consistent elution profiles between the prototype and the prepFAST-SR, individual and mixed CRM samples were prepared with $U$ and $\mathrm{Pu}$ for separation. Blanks $(\mathrm{n}=6)$ and Samples $(n=5)$ were separated each day for 3 days by different operators for a total of 33 separations per system. MC-ICP-MS results showed no significant perturbation in the major or minor isotopic ratios for either U or Pu separated fractions. Uranium blanks were consistent with previous blank studies and showed no significant quantities of $U(<0.01 \mathrm{ng})$ with near-natural isotope ratios. Plutonium blanks were also consistent with previous blank values $(<0.001 \mathrm{pg})$.

\subsection{AUTOMATED IDMS SPIKING}

Initial experiments that transferred various volumes $(0.1-10 \mathrm{~mL})$ of water between vials were carried out on the prepFAST-SR to evaluate the potential of the system for automated IDMS spiking. These experiments called into the question the ability of the software-controlled syringe pump to deliver exactly the specified amount of spike solution to a sample. Although the system exhibited high precision on the volume of spike solution delivered, the accuracy was unsatisfactory. At the typical spike volumes employed by ORNL ( $50-100 \mu \mathrm{L}$ ), the instrument delivered on average $\sim 85 \%$ of the expected value (by weight). At larger volumes, the relative offset between the user-defined value and the delivered value decreased, but the use of a more dilute spike has drawbacks for shelf life and spike equilibration. Automation of the spiking is possible, but manual weighing is still required for high confidence in the final IDMS result. Thus, automation of this step did not lead to any time savings over manual spiking using a pipette and will not continue to be pursued without a significant advancement in technology from ESI.

\subsection{BAR CODE READER}

The new systems are equipped with the hardware for the bar code reader, shown in Figure 4D. However, upon installation, the software to enable the use of the bar code reader was still under development by ESI. Currently, the systems operate properly without the bar code reader functionality. The full testing and validation of the sample tracking functionality offered by the bar code reader cannot be accomplished at ORNL until the final version of the software is made available.

\section{TIME AND COST SAVINGS}

The automation of the chemical separations step allows for unattended overnight operation of the system. ORNL NWAL manual chemistry requires 8 hours of hands-on personnel time to separate seven samples in tandem, as was documented on a recent set of actual NWAL samples. The prepFAST-MC2 (or prep $F A S T$-SR) required less than 30 minutes of hands-on personnel time before automated separations start. The time was spent adding new resin to resin bottles, changing frits, loading collection vials, and loading method(s) in the software. Once these quick activities are complete, an operator can start the system and return when the separations are completed and purified sample aliquots have been dispensed into vials. While the total amount of time spent processing IAEA swipe samples was estimated to be nearly the same, the amount of personnel time required for the ORNL NWAL manual chemistry was significantly more ( $\sim 10$ hours vs. less than 1 hour) than that required for the automated system. This time savings is graphically depicted in Figure 21 and documented in Table 14. The time savings translates to a significant cost savings, as the most expensive part of any single sample analysis is personnel labor costs. 


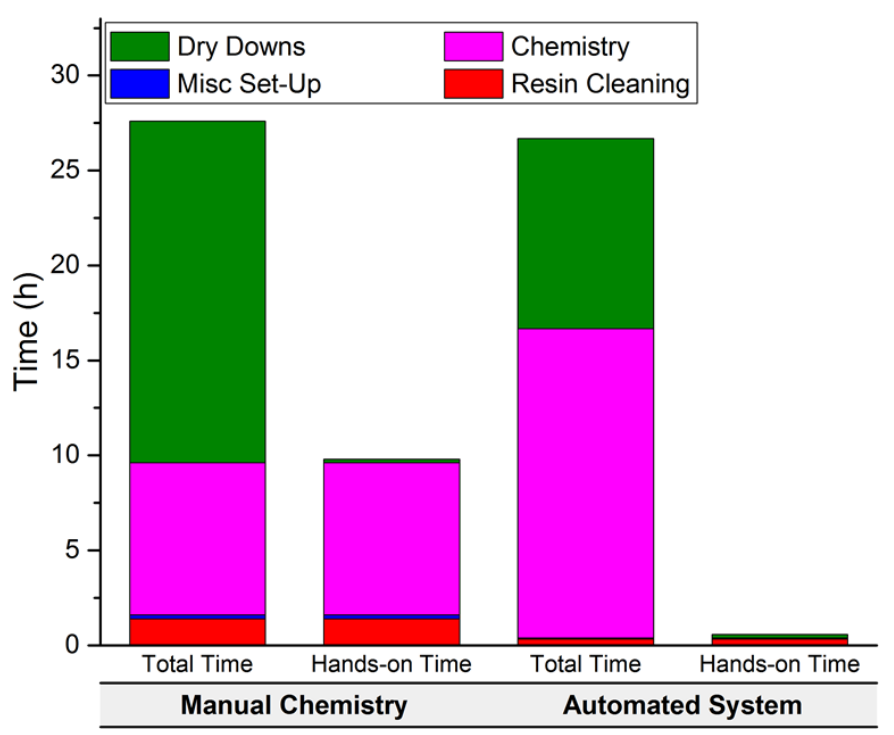

Figure 21. Time comparison chart of ORNL NWAL manual chemistry and ESI prepFAST-MC2 automated system with total time and hands-on time shown.

Table 14. Time comparison of ORNL NWAL manual chemistry and ESI prepFAST-MC2 automated system

\begin{tabular}{ccccc}
\hline \multirow{2}{*}{ Sub-steps } & \multicolumn{2}{c}{ Manual chemistry } & \multicolumn{2}{c}{ Automated system } \\
\cline { 2 - 5 } & Total time (h) & Hands-on time (h) & Total time (h) & Hands-on time (h) \\
\hline Resin cleaning & 1.4 & 1.4 & 0.33 & 0.33 \\
Misc. setup & 0.2 & 0.2 & 0.05 & 0.05 \\
Chemistry & 8 & 8 & 16.3 & 0 \\
Dry downs & 18 & 0.2 & 10 & 0.2 \\
Total & $\mathbf{2 7 . 6}$ & $\mathbf{9 . 8}$ & $\mathbf{2 6 . 6 8}$ & $\mathbf{0 . 5 8}$ \\
\hline
\end{tabular}

Additionally, it would be possible to operate several automated systems simultaneously, thus increasing throughput without adding significant hands-on personnel time. Manual chemistry is limited to processing at most a dozen samples at one time. Both the cost and the relatively small laboratory footprint make operation of multiple systems feasible, which would produce even greater efficiency gains. The use of multiple prepFAST-MC2 systems would also allow segregation of samples by content, as is typically done by NWAL laboratories already. A lab could have a prepFAST-MC2 for hot swipes and another one for cold swipes, minimizing the chance of cross-contamination between samples.

\section{CONCLUSIONS}

ORNL partnered with ESI to customize its existing prepFAST-MC to automate the separation of $\mathrm{U}$ and $\mathrm{Pu}$ from bulk environmental samples to support IAEA NWAL analysis. The resulting prototype, the prepFAST-MC2, required 35 minutes of manual preparation time and operated overnight in an unattended mode. Continuous separations can be carried out on the system if reagent levels are monitored, but one system can process only 21 samples in a $24 \mathrm{~h}$ period. However, multiple prepFAST-MC2 stations can be operated to increase sample throughput. After separations are completed, purified $\mathrm{U}$ and $\mathrm{Pu}$ aliquots for each sample are then dried down, reconstituted, and available for MC-ICP-MS analysis. 
The prepFAST-MC2 is based on the ORNL NWAL chemical procedure, which uses Eichrom UTEVA and TEVA resins to extract $\mathrm{U}$ and $\mathrm{Pu}$, respectively. The automated system packs and unpacks columns with fresh resin for each separation, avoiding potential cross-contamination from the reuse of resin. The packing step for both UTEVA and TEVA resins is critical for consistent separations, and significant effort was placed on achieving highly reproducible packing weights. The variation in the amount of packed resin was about $5 \%$, which was as good as or better than the variation in the pre-packed columns sold by Eichrom.

The elution profiles of the columns were also carefully characterized. This characterization ensured that the final method developed achieved significant separation between $\mathrm{U}$ and $\mathrm{Pu}$ in the final purified aliquots. It also helped identify the volume of the final aliquots needed to ensure complete recovery of $U$ and $\mathrm{Pu}$. Based on this data, the elution volumes were reduced for both $\mathrm{U}$ (from 5.5 to $4 \mathrm{~mL}$ ) and $\mathrm{Pu}$ (from 12 to $8 \mathrm{~mL}$ ). This reduction in elution volume may lead to cleaner blank levels and will lead to time savings by reducing dry-down times.

Finally, the low $\mathrm{U}$ and Pu blank levels initially achieved with the prepFAST-MC2 confirm that it can produce high-quality results without the need for an expensive cleanroom infrastructure. This is an especially significant advantage for many laboratories, especially internationally, that do not have the resources to support multiple cleanroom facilities.

The performance of the system was then verified by the separation of mixed U/Pu samples that consisted of isotopic CRMs. They were run interspersed with blanks and analyzed by MC-ICP-MS. The results showed that the purified samples closely matched the expected values from the certificates of the CRMs. The results indicated that the samples were not isotopically contaminated by processing and that purified aliquots are suitable for high-precision mass spectrometric analysis, both of which are essential for its eventual use in NWAL analysis. Additionally, the process blanks run between every sample contained very low levels of $\mathrm{U}(\sim 22 \mathrm{pg})$ and $\mathrm{Pu}(\sim 0.5 \mathrm{fg})$, proving that the system is completely washed out between samples, with no carryover or cross-contamination.

Finally, the time savings of the unattended, automated operation was documented directly versus the ORNL manual chemistry. For seven samples analyzed together, the total time for the automated system was 26.7 hours, versus 27.7 hours for the manual chemistry. However, when actual hands-on labor is considered, the automated chemistry required only 35 minutes of preparation time, while the manual chemistry required 9.8 hours of labor. This represents a savings of more than $90 \%$ on labor. Additionally, multiple systems could be implemented in the same laboratory to leverage the gains in the efficiency of labor.

The second generation of the automated system, the prepFAST-SR, was installed and operated at ORNL as well. Separation was initially verified using mixed U and Pu CRM samples at various concentrations. Heavy metal contaminants were also spiked into samples to ensure purification of the final $\mathrm{U}$ and $\mathrm{Pu}$ aliquots. Validation of the automated system with archived IAEA samples was successfully demonstrated, and results matched reported values. The use of the prepFAST-SR, along with other COTS equipment like the EvapoClean from Analab, creates the opportunity to conduct cleanroom-level separations without the expensive infrastructure.

\section{REFERENCES}

1. IAEA Safeguards Glossary. International Atomic Energy Agency: Vienna, 2002.

2. Recommendations from the 2010 IAEA Technical Meeting: Bulk Analysis of Environmental Samples for Safeguards; International Atomic Energy Agency: Vienna, 2010. 
3. IAEA Department of Safeguards Long-Term R\&D Plan, 2012-2023 STR-375; International Atomic Energy Agency: Vienna, 2013.

4. Development and Implementation Support Programme for Nuclear Verification 2016-2017; STR382; International Atomic Energy Agency: Vienna, 2016.

5. Field, P. M. prepFAST-MC ${ }^{T M}$ : Automating Sample Purification; Elemental Scientific Inc.: 2014.

6. Ticknor, B. W.; Bottorff, S. C.; Hexel, C. R.; Tevepaugh, K. N.; Bostick, D. A. Automated Clean Chemistry for Bulk Analysis of Environmental Swipe Samples; ORNL/TM-2016/662; Oak Ridge National Laboratory: Oak Ridge, Tennessee, 2016.

7. Ticknor, B. W.; Bottorff, S. C.; Tevepaugh, K. N.; McBay, E. H.; Bostick, D. A.; Hexel, C. R.; Kim, H.; Field, M. P., Automated Clean Chemistry for Bulk Analysis of Environmental Samples for Safeguards. 39th ESARDA Symposium on Safeguards and Nuclear Non-Proliferation 2017.

8. Ticknor, B. W.; Metzger, S. C.; McBay, E. H.; Hexel, C. R.; Tevepaugh, K. N.; Bostick, D. A. Automated Clean Chemistry for Bulk Analysis of Environmental Swipe Samples-FY 17 Year End Report; ORNL/TM-2017/710; Oak Ridge National Laboratory: Oak Ridge, Tennessee, 2017.

9. Metzger, S. C.; Ticknor, B. W.; Rogers, K. T.; Bostick, D. A.; McBay, E. H.; Hexel, C. R., Automated separation of uranium and plutonium from environmental swipe samples for multiple collector inductively coupled plasma mass spectrometry. Anal. Chem. 2018, 90 (15), 9441-9448.

10. Horwitz, E. P.; Dietz, M. L.; Chiarizia, R.; Diamond, H.; Essling, A. M.; Graczyk, D., Separation and preconcentration of uranium from acidic media by extraction chromatography. Anal. Chim. Acta 1992, $266(1), 25-37$.

11. Horwitz, E. P.; Dietz, M. L.; Chiarizia, R.; Diamond, H.; Maxwell, S. L.; Nelson, M. R., Separation and preconcentration of actinides by extraction chromatography using a supported liquid anion exchanger: application to the characterization of high-level nuclear waste solutions. Anal. Chim. Acta 1995, $310(1), 63-78$. 

APPENDIX A. CEM MICROWAVE DIGESTION REPORT 



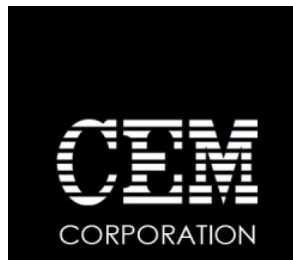

\section{APPENDIX A. CEM MICROWAVE DIGESTION REPORT}

\section{MARS 6}

\section{Laboratory Report}

(Acid Digestion)

2 Step

Date: November 16, 2016

Customer: Oak Ridge National Laboratory

Cole R. Hexel

One Bethel Valley Road

Oak Ridge TN, 37830

865-574-2449

Hexelcr@ORNL.GOV

CEM Sales: Lee Daugherty

Sample(s): Cotton Swipe, Texwipe 304, Lot \#L308AD

Equipment: Mars 6, Xpress Plus iWave

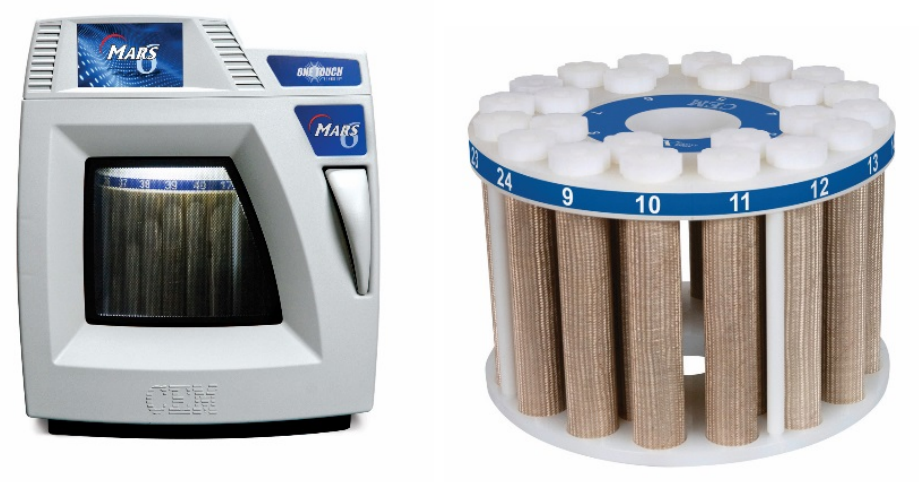

Heating Program One Touch

Organic

Ramp to Temperature

Step \#1

\begin{tabular}{|c|c|c|c|c|c|}
\hline Stage & Ramp (min) & Pressure (psi) & Temperature $\left({ }^{\circ} \mathbf{C}\right)$ & $\begin{array}{l}\text { Hold } \\
(\text { min) }\end{array}$ & Power (W) \\
\hline 1 & $20: 00$ & N/A & 120 & $10: 00$ & $280-1800$ \\
\hline
\end{tabular}


Ramp to Temperature

Organic

Step \#2

\begin{tabular}{|c|c|c|c|c|c|}
\hline Stage & Ramp (min) & Pressure (psi) & Temperature $\left({ }^{\circ} \mathbf{C}\right)$ & Hold (min) & Power (W) \\
\hline 1 & $20: 00$ & N/A & 175 & $10: 00$ & $290-1800$ \\
\hline
\end{tabular}

Analytes: U, and Pu

CEM Lab Number: D16-024-1

Reagents: $\mathrm{HNO}_{3}$ and Di Water

Number of Vessels: 8

Procedure:

1. Fold into a small square and place one swipe (approximately 2 grams) into the Xpress Plus vessel.

2. Add $10 \mathrm{ml}$ of $\mathrm{HNO}_{3}$ and $10 \mathrm{ml}$ of Di Water to the vessel.

3. Assemble the vessel without the plug by torqueing on the vessel cap.

4. Program the MARS 6 as outlined in Step \#1.

\begin{tabular}{|l|l|l|l|}
\hline \multicolumn{5}{|c|}{ Summary of Conditions During Digestion of Cotton Swipes Step \#1 } \\
\hline Temperature at End of Ramp $\left({ }^{\circ} \mathrm{C}\right)$ & 119 & Pressure at End of Ramp (psi) & N/A \\
\hline Temperature at End of Hold $\left({ }^{\circ} \mathrm{C}\right)$ & 119 & Pressure at End of Hold (psi) & N/A \\
\hline
\end{tabular}

5. Allow the sample to cool. Vent and remove the vessel cap.

6. Look inside vessels to be sure the swipes have begun to dissolve. If swipes still appear completely intact then add $5 \mathrm{ml}$ of $\mathrm{HNO}$, put the vessel caps back on and repeat Step \#1.

7. Add $5 \mathrm{ml}$ of $\mathrm{HNO}_{3}$ to the sample

8. Assemble the vessel with the plug by torqueing the vessel cap.

9. Program the MARS 6 as outlined in Step \#2

\begin{tabular}{|l|l|l|l|}
\hline \multicolumn{5}{|c|}{ Summary of Conditions During Digestion of Cotton Swipes Step \#2 } \\
\hline Temperature at End of Ramp $\left({ }^{\circ} \mathrm{C}\right)$ & 176 & Pressure at End of Ramp (psi) & N/A \\
\hline Temperature at End of Hold $\left({ }^{\circ} \mathrm{C}\right)$ & 174 & Pressure at End of Hold (psi) & N/A \\
\hline
\end{tabular}

10. Allow the sample to cool. Vent and remove the vessel cap.

11. Transfer the solution to a $50 \mathrm{~mL}$ volumetric flask and dilute to volume with deionized water 


\section{Discussion:}

Due to the large size ( 4 × 4 inches) and weight ( 2 grams) of this sample, it must be run in 2 steps. The first step is run without the plug to a low temperature of $120 \mathrm{C}$ to allow for the sample to pre-digest. The second step is run with the plugs up to $175 \mathrm{C}$ for a complete digest.

Some of these samples can go exothermic causing excessive venting. In these cases, the sample might lose volume and not be acceptable for recoveries of the analytes of interest.

Sample was clear, colorless and particle free upon dilution.

Note: This procedure has not been optimized for acid volume, temperature, pressure, and time. Acid mixtures may need optimization for some analytes and sample types.

Prepared By: Tina Restivo

Sr. Applications Chemist 

APPENDIX B. prepFAST-SR STANDARD OPERATING PROCEDURE 



\section{APPENDIX B. prepFAST-SR SOP}

1. Apparatus and Materials

1.1. prepFAST-MC-SR System

1.2. Leached sample vials and tops

1.3. 0.75 in. egg-shaped stir bars

1.4. Eichrom TEVA and UTEVA bulk resin (50-100 um mesh size)

1.5. Balance, $150 \mathrm{~g}$ or greater capacity, having an accuracy of at least $\pm 0.0001 \mathrm{~g}$

1.6. Fume hood (or ventilation for the prepFAST-MC-SR)

1.7. Adjustable pipets and leached pipet tips $(5 \mathrm{~mL}, 1 \mathrm{~mL}, 100 \mathrm{uL})$

1.8. Self-adhesive labels for sample vial identification

1.9. 10-mL disposable plastic columns set

1.10. Vacuum line or vacuum pump

1.11. 125-250 $\mathrm{mL}$ side arm filter flask with rubber septum

1.12. Vacuum tubing

1.13. $125 \mathrm{~mL}$ PFA squirt bottle

1.14. $50 \mathrm{~mL}$ centrifuge tubes

1.15. $20 \mathrm{~mL}$ graduated cylinder (or pipets can be used to measure out the volumes for washing the resin before transfer to resin bottle)

1.16. $15 \mathrm{~mL}$ centrifuge tube holder

1.17. $50 \mathrm{~mL}$ centrifuge tube holder

2. Standards and Reagents

2.1. ASTM Type I reagent-grade water, $18 \mathrm{M} \Omega$

2.2. $\mathrm{HNO}_{3}$, Ultrex grade (or equivalent)

2.3. HF, Ultrex grade (or equivalent)

2.4. $\mathrm{HCl}$, Ultrex grade (or equivalent)

2.5. $\mathrm{H}_{2} \mathrm{O}_{2}$, Ultrex grade (or equivalent)

2.6. $8 \mathrm{M} \mathrm{HNO}_{3}$

2.7. $8 \mathrm{M} \mathrm{HNO}_{3}-0.1 \mathrm{M} \mathrm{HF}$

2.8. $3 \mathrm{M} \mathrm{HNO}_{3}$

2.9. $0.01 \mathrm{M} \mathrm{HNO}_{3}$

2.10. $9 \mathrm{M} \mathrm{HCl}$

2.11. $0.02 \mathrm{M} \mathrm{HNO}_{3}-0.005 \mathrm{M} \mathrm{HF}$

2.12. $0.1 \mathrm{M} \mathrm{HCl}-0.06 \mathrm{M} \mathrm{HF}$

2.13. $2 \% \mathrm{HNO}_{3}$

2.14. $5 \% \mathrm{HNO}_{3}$

2.15. $3 \mathrm{M} \mathrm{NaNO}_{2}$, ultra-pure, $0.51 \mathrm{~g}$ dissolved in $2.4 \mathrm{~mL}$ water $(0.4 \mathrm{~mL} / \mathrm{sample})$

2.16. $1.7 \mathrm{M} \mathrm{FeSO}_{4}$, ultra-pure, $0.96 \mathrm{~g}$ dissolved in $2 \mathrm{~mL}$ water $(0.2 \mathrm{~mL} / \mathrm{sample})$

3. Preparation of TEVA and UTEVA Bulk Resin

3.1. Prepare $10 \mathrm{~mL}$ plastic disposable columns with a frit at the bottom of each column and place a cap on the bottom tip of the column. Place prepared empty column into a $50 \mathrm{~mL}$ centrifuge tube or $15 \mathrm{~mL}$ centrifuge tube rack holder. 
3.2. Tare empty column (in centrifuge tube). Add $\sim 4.00-4.04 \mathrm{~g}$ of respective resin to the column and reweigh. Record results as the "Resin Weight." (Weight range should be $\sim 1 \%$.) Label column with resin type and weight and place top cap on column for storage until use.

3.3. TEVA cleaning and suspension:

3.3.1. Remove top and bottom cap from column (do not dispose of bottom cap). Place column in rubber stopper in side arm vacuum flask and start vacuum. Rinse TEVA resin with $3 \mathrm{M}$ $\mathrm{HNO}_{3}(15 \mathrm{~mL})$.

3.3.2. Stop vacuum and remove column from rubber stopper.

3.3.3. Replace bottom cap on column.

3.3.4. Weigh out $50 \mathrm{~mL}$ of $3 \mathrm{M} \mathrm{HNO}_{3}(\sim 55.0 \mathrm{~g})$ into a PFA squirt bottle. Record weight as "Resin Suspension Weight."

3.3.5. Using the squirt bottle, resuspend the resin in the column in small increments and pour resin into TEVA resin bottle for use on the prepFAST-SR.

3.3.6. Once all resin is in resin slurry bottle, use any remaining $3 \mathrm{M} \mathrm{HNO}_{3}$ to rinse the tip of the squirt bottle into the slurry bottle.

3.4. UTEVA cleaning and suspension:

3.4.1. Remove top and bottom cap from column (do not dispose of bottom cap). Place column in rubber stopper in side arm vacuum flask and start vacuum. Rinse TEVA resin with $0.01 \mathrm{M}$ $\mathrm{HNO}_{3}(15 \mathrm{~mL})$. Followed by $3 \mathrm{M} \mathrm{HNO}_{3}(5 \mathrm{~mL})$.

3.4.2. Stop vacuum and remove column from rubber stopper.

3.4.3. Replace bottom cap on column.

3.4.4. Weigh out $50 \mathrm{~mL}$ of $3 \mathrm{M} \mathrm{HNO}_{3}(\sim 55.0 \mathrm{~g})$ into a PFA squirt bottle. Record weight as "Resin Suspension Weight."

3.4.5. Using the squirt bottle, resuspend the resin in the column in small increments and pour resin into UTEVA resin bottle for use on the prepFAST-SR.

3.4.6. Once all resin is in resin slurry bottle, use any remaining $3 \mathrm{M} \mathrm{HNO}_{3}$ to rinse the tip of the squirt bottle into the slurry bottle.

3.5. Attach resin slurry feed lines to designated vial and place slurry bottles on stir plates in prepFAST-SR lower cabinet.

3.6. Stir resin mixture for $\sim 20$ min or until all fines are mixed in from the top of the solution. (This step can occur while samples are loaded into autosampler trays and methods are loaded into the ESI software.)

4. Column Separation of $\mathrm{U}$ and $\mathrm{Pu}$ (assuming samples are already digested, spiked if necessary, and in $\left.3 \mathrm{M} \mathrm{HNO}_{3}[1-3 \mathrm{~mL}]\right)$

4.1. Add $0.2 \mathrm{~mL} 1.7 \mathrm{M} \mathrm{FeSO}_{4}$ to each vial and mix for $\sim 5 \mathrm{~min}$. When the solution color changes from dark to light, add $0.4 \mathrm{~mL} 3 \mathrm{M} \mathrm{NaNO} 2$ and wait for the solutions to degas ( $\sim 15 \mathrm{~min}$ ).

Samples should be capped immediately after adding the $\mathrm{NaNO}_{2}$ solution.

4.2. Place samples in autosampler tray in prep $F A S T$-SR.

4.3. Place labeled collection vials into autosampler tray(s) in prepFAST-SR.

4.4. Software Setup:

4.4.1. Click "Configure"

4.4.2. Choose "prepFAST Offline"

4.4.3. Select "Enable prepFAST-MC2" or "Enable prepFAST-SR" depending on software version

4.4.4. Complete the sample log for Sample ID, Sample Vial, and Destination 1 and 2 vial locations 
4.4.4.1. Sample ID: Name of sample

4.4.4.2. Sample Vial: Autosampler tray location of sample

4.4.4.3. Destination 1 Vial: $U$ fraction vial collection location

4.4.4.4. Destination 2 Vial: Pu fraction vial collection location

4.4.4.5. Destination 3 Vial: blank

4.4.5. Select FAST Method File: IAEA in sample one. Right click on the method name and select "Set Submethod Parameters."

4.4.5.1. Double-check submethod parameters are correct for the samples selected and save any changes.

4.4.6. Right click on the method name in Sample 1 and select "Copy Cell Contents To All Cells Below."

4.5. Uncap all vials, double-check vial locations, and select "Start prepFAST."

4.6. Cap samples after all samples are complete.

5. Matrix Conversion

5.1. Dry down the $\mathrm{U}$ and $\mathrm{Pu}$ fractions in an evaporation box or on the EvapoClean system.

5.2. Remove column organics by adding $25 \mu \mathrm{L} 8 \mathrm{M} \mathrm{HNO}_{3}$ plus $25 \mu \mathrm{L} \mathrm{H}_{2} \mathrm{O}_{2}$ and heating the sample at $60{ }^{\circ} \mathrm{C}$ for $20 \mathrm{~min}$; dry down, repeat.

5.3. Add $15 \mu \mathrm{L} 8 \mathrm{M} \mathrm{HNO}_{3}$ to dissolve the residue before adding $1.5 \mathrm{~mL} 2 \% \mathrm{HNO}_{3}$ to the vials containing the $\mathrm{U}$ and $\mathrm{Pu}$ fractions.

5.4. Submit for MS analysis.

6. If the $\mathrm{U} / \mathrm{Pu}$ in the original sample was $>1 \mathrm{e} 04$, as determined by initial screen results, the $\mathrm{Pu}$ fraction may need to be passed through a second TEVA column to reduce the $\mathrm{U}$ in the final $\mathrm{Pu}$ fraction. 